\title{
Initial Suppression of Transforming Growth Factor- $\beta$ Signaling and Loss of TGFBI Causes Early Alveolar Structural Defects Resulting in Bronchopulmonary Dysplasia
}

\author{
Shawn K. Ahlfeld, Jian Wang, Yong Gao, Paige Snider, and Simon J. Conway
}

From the HB Wells Center for Pediatric Research, Indiana University School of Medicine, Indianapolis, Indiana

\author{
Accepted for publication \\ November 18, 2015. \\ Address correspondence to \\ Simon J. Conway, Ph.D., \\ Indiana University School of \\ Medicine, 1044 W Walnut St, \\ Room R4 W402F, Indianapolis, \\ IN 46202. E-mail: siconway@ \\ iu.edu.
}

\begin{abstract}
Septation of the gas-exchange saccules of the morphologically immature mouse lung requires regulated timing, spatial direction, and dosage of transforming growth factor (TGF)- $\beta$ signaling. We found that neonatal hyperoxia acutely initially diminished saccular TGF- $\beta$ signaling coincident with alveolar simplification. However, sustained hyperoxia resulted in a biphasic response and subsequent upregulation of TGF- $\beta$ signaling, ultimately resulting in bronchopulmonary dysplasia. Significantly, we found that the TGF- $\beta$-induced matricellular protein (TGFBI) was similarly biphasically altered in response to hyperoxia. Moreover, genetic ablation revealed that TGFBI was required for normal alveolar structure and function. Although the phenotype was not neonatal lethal, Tgfbi-deficient lungs were morphologically abnormal. Mutant septal tips were stunted, lacked elastin-positive tips, exhibited reduced proliferation, and contained abnormally persistent alveolar $\alpha$-smooth muscle actin myofibroblasts. In addition, Tgfbi-deficient lungs misexpressed TGF- $\beta$-responsive follistatin and serpine 1 , and transiently suppressed myofibroblast platelet-derived growth factor $\alpha$ differentiation marker. Finally, despite normal lung volume, Tgfbi-null lungs displayed diminished elastic recoil and gas exchange efficiency. Combined, these data demonstrate that initial suppression of the TGF- $\beta$ signaling apparatus, as well as loss of key TGF- $\beta$ effectors (like TGFBI), underlies early alveolar structural defects, as well as long-lasting functional deficits routinely observed in chronic lung disease of infancy patients. These studies underline the complex (and often contradictory) role of TGF- $\beta$ and indicate a need to design studies to associate alterations with initial appearance of phenotypical changes suggestive of bronchopulmonary dysplasia. (Am J Pathol 2016, 186: 777-793; http:// dx.doi.org/10.1016/j.ajpath.2015.11.024)
\end{abstract}

Throughout late fetal and early neonatal life, to dramatically increase the surface area for gas exchange, the saccular lung prepares to undergo the process of secondary septation. ${ }^{1}$ During this critical transitional period, there is additional branching, lengthening, and widening of the future alveolar ducts in the periphery of the lung at the expense of mesenchyme. ${ }^{2}$ Saccular maturation and secondary septation are reliant on the interplay between diverse signaling pathways, growth factors, transcription factors, and extracellular matrix (ECM) components to establish and orchestrate timely remodeling of lung structure and function in vivo. ${ }^{3,4}$ When lung developmental networks that direct secondary septation are interrupted (even briefly), the result is distal lung simplification with a reduced surface area for gas exchange contributing to significant morbidity and profound pathological consequences that can remain throughout a

\footnotetext{
Supported, in part, by the Indiana University School of Medicine Indiana Pediatric Scientist Award program through the Child Health Research Career Development Award K12 HD068371 (S.K.A.) and NIH grant R01 HL115619 (S.J.C.).

Disclosures: None declared.

Current address for S.K.A., Division of Neonatology and Pulmonary Biology, Cincinnati Children's Hospital and Medical Center, Cincinnati, $\mathrm{OH}$.
} 
lifetime. ${ }^{5-8}$ Although essential for life, exposing the developing lung to relative high oxygen concentration, as occurs with extreme preterm birth, is thought to adversely inhibit saccular lung development and secondary septation, ${ }^{5-7}$ resulting in bronchopulmonary dysplasia (BPD). Because protective therapeutic strategies have thus far been ineffective in reducing BPD and most infants born extremely premature continue to develop BPD, ${ }^{9}$ it is critical to identify novel therapeutic targets for translational approaches, prevention, and/or correction of BPD in patients.

BPD is primarily a disease of alveolar-capillary membrane simplification, resulting from injury to the developing saccular lung. ${ }^{10}$ Alveolar-capillary membrane simplification is linked to abnormalities in the lung mesenchyme and its associated ECM proteins and growth factors. ${ }^{11,12}$ Of the growth factors known to influence mesenchymal homeostasis, one that has received considerable interest is transforming growth factor (TGF)- $\beta$. TGF- $\beta$ promotes ECM formation by increasing production of collagens and fibronectin ${ }^{13}$ and preventing ECM degradation by inhibiting proteases and up-regulating protease inhibitors. ${ }^{14}$ TGF- $\beta$ can also induce expression of tropoelastin from lung fibroblasts, ${ }^{15}$ which is essential to distal lung morphogenesis. ${ }^{16}$ Signaling is accomplished when one of three ligands (TGF $\beta-1$, TGF $\beta-2$, or TGF $\beta-3$ ) binds to common type II receptor (TBRII), which then recruits and phosphorylates one of several type I receptors. ${ }^{17}$ After activation by TBRII, type I receptors phosphorylate intracellular Smad2 and/or Smad3, which complex with co-Smad4 and translocate to the nucleus to stimulate downstream target expression. TGF- $\beta$ ligands are secreted in an inactive state, bound to ECM latent TGF- $\beta$ binding proteins; thus, the matrix serves as a TGF- $\beta$ sink. All three ligands, their receptors, and $\operatorname{Smad} 2 / 3$ are spatiotemporally regulated throughout saccular and alveolar stages, ${ }^{18}$ suggesting they are actively involved in normal lung development. However, the downstream mediators of TGF- $\beta$ signaling essential to accomplish normal alveolar septation are relatively unknown.

Exposure of the neonatal rodent lung to hyperoxia during postnatal saccular and early alveolar lung development [which occurs in the mouse approximately between birth and postnatal (P) day 7] reliably inhibits secondary septation and has provided insight into the molecular pathways critical to alveolar lung development. ${ }^{19-21}$ We have recently shown that brief exposure to hyperoxia during the first 4 to 7 postnatal days lastingly inhibits alveolar septation and results in alveolar simplification and reduced gas exchange in adult animals. ${ }^{22,23}$ Moreover, hyperoxia disrupted expression of periostin, a matricellular protein regulated by TGF- $\beta$ signaling. ${ }^{22}$ Using the well-established neonatal hyperoxia model, we present novel data indicating that TGF- $\beta$ signaling is impaired at multiple levels during a critical period of postnatal lung morphogenesis, resulting in inhibition of secondary alveolar septation via dysregulated alveolar fibroblast maturation. Furthermore, we identify a novel downstream target of TGF- $\beta$ signaling, TGF- $\beta$-induced matricellular protein (TGFBI), as a required component of the distal lung ECM that is necessary for normal alveolar secondary septation.

\section{Materials and Methods}

\section{Gene Targeting and Hyperoxia Exposure}

To generate $T g f b i^{\text {lac } Z}$ knockin mice, we screened a $129 \mathrm{SvJ}$ mouse embryonic stem cell genomic DNA library (Genome System Inc., St. Louis, MO) by PCR and identified a bacterial artificial chromosome clone that contains the genomic DNA that codes for the Tgfbi gene. Bacterial artificial chromosome DNA was isolated using a large-construct purification kit (Qiagen, Valencia, CA), and Southern blots were used to confirm the identity and integrity of the clone. A replacement-targeting vector was constructed where the bacterial $\beta$-galactosidase gene was knocked into the $T g f b i$ gene locus. The $5^{\prime}$ homology arm, a 3-kb DNA fragment that contains all of the $5^{\prime}$ untranscribed region and promoter elements, was PCR amplified using a high-fidelity Thermal Ace DNA polymerase kit (Invitrogen, Carlsbad, CA). In the PCR, these primers were engineered to produce $5^{\prime}$ Sall and $3^{\prime}$ XhoI sites, which enabled us to directionally clone the insert in frame with a promoterless IRES-lacZ-neo-loxP cassette. ${ }^{24}$ The resultant vector expressed the $l a c Z$ reporter under the control of the endogenous Tgfbi promoter. A 3.5-kb Sal1EcoRI $3^{\prime}$ homology arm was cloned in frame into the $3^{\prime}$ end of the floxed IRES-lacZ-neo-loxP cassette. This resulted in a targeting vector where the translation start site and all of the first exon were deleted. After sequencing verification, the complete targeting construct was cloned into the thymidine kinase-negative selection vector, as described. ${ }^{24}$ Southern hybridization using both $3^{\prime}$ external probe and $5^{\prime}$ internal probes on BamHI-digested DNA was used for both primary and secondary screening. The $3^{\prime}$ external probe was the primary screen where the wild-type allele $(8.3 \mathrm{~kb})$ can be easily distinguished from the larger targeted allele (approximately $16 \mathrm{~kb}$ ). Five correctly targeted embryonic stem clones were identified, and used to generate chimeras that were subsequently bred with $\mathrm{C} 57 \mathrm{BL} / 6 \mathrm{~J}$ mice for six generations. Southern and PCR genotyping (primers 5'-TGTCCGTGCCTAAGTGTGAG- $3^{\prime}$ and $5^{\prime}$-CAGCAGCAGACCATTTTCAA- $3^{\prime}$ to detect null allele approximately $399 \mathrm{bp}$; $5^{\prime}$-TCAACAGCCACAGTGAAAGG- $3^{\prime}$ and $5^{\prime}$-GCCTGTAACCATTTGCCACT- $3^{\prime}$ to detect wild-type allele approximately $520 \mathrm{bp}$ ) was used to identify $T g f b i^{\text {lac } Z}$ heterozygotes, which were bred to a Cre splicer mouse (EIIa-Cre) to remove the neomycin resistance cassette. Mice were backcrossed to C57BL/6J mice to remove the Cre allele, maintained on a C57BL/6J background, and interbred to generate homozygotes.

For the hyperoxia studies, two or more litters of wild-type C57BL/6J (The Jackson Laboratory, Bar Harbor, ME) mice born within 6 hours of one another were pooled and separated into two equal groups of six to eight mice by 12 hours of age. Half of the pups were maintained in a $30 \times 20 \times 20$-inch polypropylene chamber (BioSpherix, Lacona, NY) in which the 
oxygen concentration was tightly controlled at $85 \% \mathrm{O}_{2}$, and the other half were maintained in room air $\left(21 \% \mathrm{O}_{2}\right)$, as described. ${ }^{22}$ Nursing dams were rotated between groups every 48 hours to prevent oxygen toxicity to the dams, and pups were continuously exposed until harvested for analysis at P2, P4, P7, and P14. All procedures were performed with the approval of the Institutional Animal Care and Use Committee of Indiana University School of Medicine (Indianapolis, IN; protocol 10107).

\section{Lung Histology and Morphometric Analysis}

After euthanization and aortic transection, the right ventricle was injected with cold phosphate-buffered saline until the lungs were visually clear of blood. A tracheotomy was performed, and a 22-gauge syringe adapter was inserted and secured with suture. With chest closed to avoid overdistension, lungs were inflation fixed with $4 \%$ paraformaldehyde at a constant pressure of $25 \mathrm{~cm} \mathrm{H}_{2} \mathrm{O}$ for 45 minutes, then the heart and lungs were removed en bloc and fixed in $4 \%$ paraformaldehyde overnight at $4{ }^{\circ} \mathrm{C}$, as described. ${ }^{22}$ The entire left lobe of each animal was paraffin embedded and divided into serial sections $(7 \mu \mathrm{m}$ thick) in entirety. Serial, equidistant sections through the entire left lung were hematoxylin and eosin stained, and random fields containing distal airspaces were photographed with a $20 \times$ objective on a Zeiss Axioskop2Plus Microscope (Carl Zeiss Inc., Thornwood, NY) at $1292 \times 968$ pixels. To assess distal airspace maturation, computer-aided morphometric analysis was performed using ImageJ software version 1.44 (NIH, Bethesda, MD) to measure mean linear intercept, nodal density, and septal thickness, as previously described. ${ }^{22}$ For all morphometric analyses, 12 nonoverlapping fields from at least six slides per animal were obtained, and at least four to eight animals per condition at each time point were examined. Only fields consisting of alveolar septa were used for analysis; fields containing large vessels, conducting airways, or sectioning artifacts were avoided.

\section{Transmission Electron Microscopy}

Transmission electron microscopy sample isolation, fixation, and processing were performed as previously described. ${ }^{24,25}$ Briefly, P4 lung lobes were fixed with $4 \%$ paraformaldehyde and $2 \%$ glutaraldehyde solution buffered at $\mathrm{pH} 7.4$ with $0.1 \mathrm{~mol} / \mathrm{L}$ sodium cacodylate. Specimens were then washed and dehydrated in an ethanol series, embedded in Polybed 812 resin (Polyscience, Warrington, PA), polymerized for 72 hours at $60^{\circ} \mathrm{C}$, divided into thin sections with a Sorvall MT 5000 ultramicrotome (Sorvall, Norwalk, CT), and mounted on copper grids. Sections were stained with uranyl acetate and lead citrate and viewed with a FEI-Philips SM12 STEM (Hillsboro, OR).

\section{Assessment of $\mathrm{DF}_{\mathrm{CO}}$ and in Vivo Lung Compliance}

After anesthesia and tracheotomy, an 18-gauge cannula was inserted and mice were mechanically ventilated with a
flexiVent (SCIREQ, Montreal, ON, Canada) using $100 \% \mathrm{O}_{2}$, a tidal volume of $10 \mathrm{~mL} / \mathrm{kg}$ at a rate of 150 breaths/minute, and a positive end-expiratory pressure of $3 \mathrm{~cm} \mathrm{H}_{2} \mathrm{O}$. The pulmonary elastic properties were evaluated from quasistatic pressurevolume curves obtained in vivo. Mechanical ventilation of the anesthetized animals was interrupted, and the pulmonary system was cycled in step-wise increments between the endexpiratory pressure of $3 \mathrm{~cm} \mathrm{H}_{2} \mathrm{O}$ and a maximal airway pressure of $20 \mathrm{~cm} \mathrm{H}_{2} \mathrm{O}$. To control for varying degrees of atelectasis and total lung capacity between animals, pressurevolume curves were normalized to the maximal inspiratory lung volume at $20 \mathrm{~cm} \mathrm{H}_{2} \mathrm{O}$, and only the expiratory portion of the curve was examined to determine elastic properties. The operation was performed in triplicate and averaged for each animal. Immediately after assessment of lung compliance, the diffusing factor for carbon monoxide $\left(\mathrm{DF}_{\mathrm{co}}\right)$ was assessed, as previously described. ${ }^{23}$ Briefly, lungs were inflated via a tracheal catheter containing $0.8 \mathrm{~mL}$ of test gas $(0.5 \% \mathrm{Ne}, 0.5 \%$ $\mathrm{CO}, 20 \% \mathrm{O}_{2}$, and balanced nitrogen) and held for 6 seconds. Then, the exhaled gas was diluted with room air (RA) to a final volume of $2 \mathrm{~mL}$, and concentrations of neon and carbon monoxide were immediately determined using a 3000Micro GC bench-top gas chromatographer (INFICON, East Syracuse, NY). $\mathrm{DF}_{\mathrm{co}}$ was calculated, as described, ${ }^{23}$ and measurements were obtained in triplicate, with each measurement separated by a 150 -second period of mechanical ventilation to ensure disappearance of carbon monoxide and neon from the previous measurement. For each animal, $\mathrm{DF}_{\mathrm{co}}$ was expressed as the average of the three measurements.

\section{Immunohistochemistry, in Situ Hybridization, and X-Gal Analysis}

Immunohistochemical staining used the Vectastain Elite $\mathrm{ABC}$ kit (Vector Labs, Burlingame, CA) with diaminobenzidine (Vector Labs) and hydrogen peroxide as chromogens. Dilution of primary antibodies was 1:100 for rabbit anti-TGFBI (ProteinTech, Chicago, IL), 1:500 for rabbit anti-follistatin (ProteinTech), 1:2500 for rabbit antivon Willebrand factor (Dako, Carpinteria, CA), 1:250 for rabbit anti-pro-surfactant protein $\mathrm{C}$ (Abcam, Cambridge, MA), 1:25 for rat anti-Ki-67 (Abcam), 1:200 for platelet endothelial cell adhesion molecule-1 (BD Biosciences Pharmingen, San Jose, CA), and 1:5000 for rat anti- $\alpha$ smooth muscle actin ( $\alpha$-SMA; Sigma-Aldrich, St. Louis, MO). Confocal imaging of $\alpha$-SMA, Pro-SPC, lacZ, and DAPI nuclear marker colocalization was performed as described. ${ }^{26}$ Proliferation and cellularity were assessed on Ki-67-stained lung sections. The proliferative index was calculated as the percentage of Ki- $67^{+}$nuclei per $20 \times$ field. Cellularity was determined as the total number of nuclei per $20 \times$ field, normalized to the percentage tissue density, and expressed as nuclei per millimeter. ${ }^{2}$ Terminal deoxynucleotidyl transferase-mediated dUTP nick-end labeling staining was detected in paraffin sections using the In Situ Cell Death Detection kit (Roche, Indianapolis, IN), and 
elastin fiber deposition was identified via Weigert's Resorcin Fuchsin stain (Electron Microscopy Sciences, Hatfield, PA). Wild-type littermates were always used as age-matched controls. Sense and anti-sense $\left[{ }^{35}\right.$ S $]$ UTP-radiolabeled Tgfbi, ${ }^{27}$ Tgfb $1,2,3,{ }^{28}$ Pdgf receptor- $\alpha,{ }^{29}$ Clara cell secretory protein, and serpine 1 RNA probes were transcribed for in situ hybridization, as described. ${ }^{30}$ Specific signal was observed only with the anti-sense probe and detected in at least three consecutive sections. Isolation of tissues, fixation, processing, and whole-mount staining for $\beta$-galactosidase were performed as described. ${ }^{24}$ Subsequently, X-Gal-stained lungs were fixed, wax embedded, divided into serial sections (10 $\mu \mathrm{m}$ thick), and counterstained with eosin. For all histological analyses, 12 nonoverlapping fields from at least three slides per animal were obtained, and at least four to eight animals per condition at each time point were examined. Only fields consisting of alveolar septa were used for analysis.

\section{Western Blot Analysis}

Western blot analysis was performed as described. ${ }^{24,25}$ Proteins isolated from P2, P4, P7, and P14 left lungs of wild-type, $T g f b i^{l a c Z}$, and $85 \% \mathrm{O}_{2}$ hyperoxic mice were probed with TGFBI (1:250; R\&D Systems, Minneapolis, MN), phospho-Smad1/5/8 (1:1000; Cell Signaling, Danvers, MA), phospho-Smad3 (1:1000; Epitomics, Burlingame, CA), phospho-Smad2 (1:1000; Cell Signaling), total Smad2,3 (1:1000; Cell Signaling), total Smad3 (1:1000; Epitomics), $\alpha$-SMA (1:75,000; Sigma-Aldrich), and loading control $\alpha$-tubulin (1:10,000; Sigma-Aldrich). Signal was detected via ECL-plus (Amersham, Pittsburgh, PA), and densitometric quantification of Western blot data ( $n=3$ to 6 lungs per genotype) was analyzed using ImageJ software version 1.44 (NIH, Bethesda, MD; http://imagej.nih.org/ij).

\section{qPCR Analysis}

To examine $\operatorname{Tgf} \beta 1$, $\operatorname{Tgf} \beta 2$, and $\operatorname{Tgf} \beta 3$ ligand expression temporal levels within neonatal wild-type and $85 \% \quad \mathrm{O}_{2}$ hyperoxic lungs, we used quantitative PCR (qPCR) on cDNA synthesized from $\mathrm{P} 2, \mathrm{P} 4, \mathrm{P} 7$, and $\mathrm{P} 14$ lungs ( $n=4$ lungs per exposure per time point) using a Superscript-II kit (Invitrogen). cDNA was amplified within the linear range using primers (Tgf $\beta 1$ PPM02991B-200, Tgf $\beta 2$ PPM02992A-200, and Tgf 33 PPM02993A-200; Qiagen) and normalized to GAPDH (PPM02946E-200), using RT ${ }^{2}$ SYBR Green qPCR Mastermix Kit (Qiagen), as described. ${ }^{25}$ To examine Tgfbi, follistatin, and elastin expression in response to $85 \% \mathrm{O}_{2}$ hyperoxia and within Tgfbi nulls, we used qPCR on cDNA synthesized from wild-type, $85 \% \mathrm{O}_{2}$-exposed, and $T g f b i$-null P4, P7, and P14 lungs $(n=4$ lungs per exposure per time point) using a Superscript-II kit. cDNA was amplified within the linear range using primers (Tgfbi, Fst, and Elastin; Qiagen) and normalized with GAPDH, as above. To assess TGF- $\beta$ superfamily expression profiles in wild-type, $\operatorname{Tgfbi}^{\text {lac } Z}$, and
$85 \% \mathrm{O}_{2}$ hyperoxic $\mathrm{P} 4$ lungs, we used qPCR on cDNA synthesized from left lung isolates using a Superscript-II kit. mRNA from P4 left lungs ( $n=4$ pooled for each genotype) was isolated using RNAEasy (Qiagen) kit and reverse transcribed using SuperScript II Reverse Transcriptase (Thermo Fisher Scientific, Waltham, MA). Two samples per genotype were used in the Mouse TGF- $\beta /$ Bmp Signaling Pathway RT ${ }^{2}$ Profiler PCR Array (Qiagen), and qPCR was performed in technical triplicate for each sample, as described. ${ }^{25}$ All qPCR data are representative of three separate experiments $(n=3$ plates per genotype), and $\Delta \Delta \mathrm{C}_{\mathrm{t}}$-based fold-changes were calculated using $G A P D H$ as a standard.

\section{Statistical Analysis}

Statistical analysis was performed with Prism software version 5.02 (Graphpad Software, San Diego, CA). Comparisons between experimental groups (RA versus $\mathrm{O}_{2}$ or wild type versus $T g f b l^{\text {iac } Z}$ nulls) were made using unpaired $t$-test. $P<0.05$ was considered statistically significant. All data are presented as means \pm SEM. For statistical analysis of quantitative PCR data, cDNAs from wild-type, $T g f b l^{\text {lac }}$, and $85 \% \mathrm{O}_{2}$ hyperoxic $\mathrm{P} 4, \mathrm{P} 7$, and $\mathrm{P} 14$ lungs $(n=4$ pooled left lung samples for each genotype) were analyzed in triplicate for each transcript.

\section{Results}

\section{Atypical TGF- $\beta$ Signaling in Response to Hyperoxia Exposure during a Critical Period of Early Alveolar Development}

We previously demonstrated that the TGF- $\beta$-responsive matricellular protein, periostin, was robustly expressed in the developing distal airspaces of the mouse saccular lung, and that continuous neonatal hyperoxia exposure from postnatal birth onward resulted in dynamic biphasic misexpression. ${ }^{22}$ Initially, periostin was suppressed during early lung alveolar septation but was subsequently up-regulated at P14, concomitant with a fibrotic response. ${ }^{22}$ Furthermore, we found exposure of neonatal mouse lungs to hyperoxia restricted to as little as 4 days (from P0 to P4) resulted in persistent simplification of distal lung structure and inhibited adult lung function. ${ }^{22,23}$ Because it was unexpected that suppressed TGF- $\beta$ signaling would be associated with defective alveolar septation, and to better define the contributions of the extracellular, intracellular, and downstream products of TGF- $\beta$ signaling during both normal and hyperoxia-inhibited alveolar development, we used qPCR to examine the relative mRNA expression levels of all three TGF- $\beta$ ligands during early alveolar development (P2 to P7) (Figure 1A). Although Tgf $\beta 1$ was the predominate isoform at $\mathrm{P} 2$, at $\mathrm{P} 4$ there was down-regulation of $\operatorname{Tgf} \beta 1$ with relative persistence of $\operatorname{Tgf} \beta 2$, resulting in equal expression of the two isoforms. By P7, during peak alveolar development, Tgf $\beta 2$ persisted as the dominate isoform. Although 

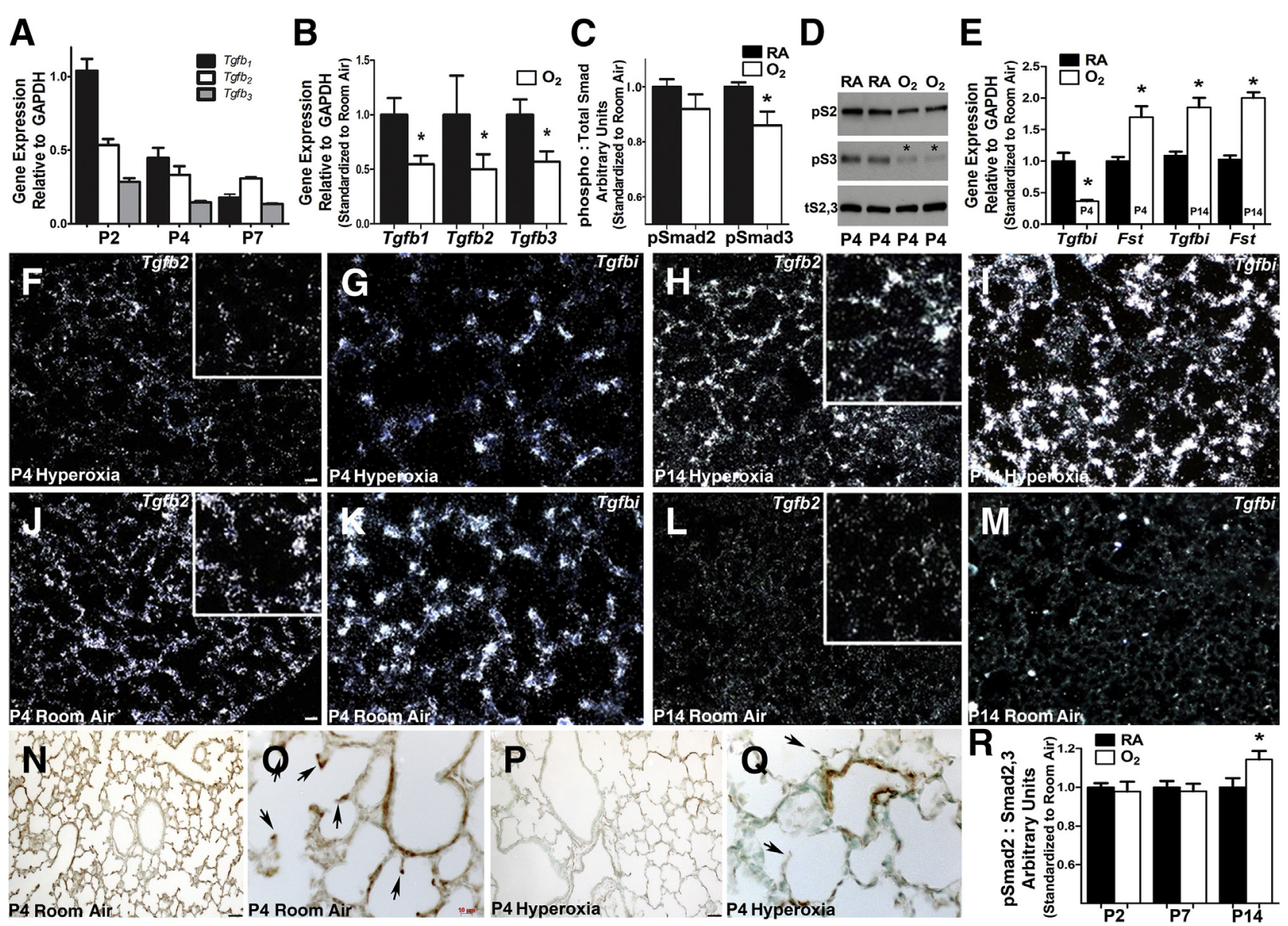

Figure 1 Hyperoxia acutely diminishes saccular lung transforming growth factor (TGF)- $\beta$ superfamily signaling and misexpression of down-stream targets. A: Quantitative PCR ( $q P C R$ ) analysis of relative whole lung transforming growth factor (Tgf) $\beta 1$, Tgf $\beta 2$, and Tgf $\beta 3$ ligand mRNA expression levels during normal postnatal saccular (P2, P4) and early alveolar (P7) lung development in room air (RA) control mice. B: qPCR assessment of Tgf $\beta 1$, Tgf $\beta 2$, and Tgf $\beta 3$ mRNA expression reveals all three ligands are suppressed in $\mathrm{P} 4$ lungs exposed continuously to $85 \%$ hyperoxia (oxygen) when compared with normal RA. C and D: Morphometric quantitation (C) of Western measurement of phosphorylated Smad2 and Smad3 protein levels (D) confirms that intracellular TGF- $\beta$ canonical Smad-mediated signaling is suppressed in $\mathrm{P} 4$ lungs (asterisk) exposed to $85 \% \mathrm{O}_{2}$, when compared with room air (RA) P4 littermate lungs and total Smad2 and Smad3 levels. E: qPCR mRNA profiling of 84 TGF- $\beta$-responsive genes reveals that, in addition to Tgf $\beta$ ligands, two downstream targets are statistically misexpressed (asterisk) at P4 and P14 after $85 \% \mathrm{O}_{2}$ exposure. Specifically, Tgfbi mRNA levels are suppressed, whereas follistatin (Fst) mRNA levels increase via $85 \% \mathrm{O}_{2}$ when compared with RA controls at P4. However, both Tgfbi and Fst are elevated via $85 \% \mathrm{O}_{2}$ when compared with RA controls at P14. F-I: In situ hybridization of altered $\operatorname{Tgf} \beta 2(\mathbf{F}$ and $\mathbf{H})$ and Tgfbi $(\mathbf{G}$ and $\mathbf{I})$ at P4 and P14 mRNA expression within alveolar tissue sections in animals continuously exposed to $85 \% \mathrm{O}_{2}$. Note the more punctate Tgfbi saccular wall expression when compared with Tgf $\beta 2$. J-M: In situ hybridization verification of normal Tgf $\beta 2(\mathbf{J}$ and $\mathbf{L})$ and Tgfbi ( $\mathbf{K}$ and $\mathbf{M})$ at P4 and P14 in RA control animals. Enlarged insets (F, H, J, and $\mathbf{L})$ show expression at developing septal tips. N-Q: Immunohistochemical analysis confirms that the reduction in mRNA expression translates to a reduction in TGFBI protein expression in P4 lungs from animals continuously exposed to $85 \% \mathrm{O}_{2}$ when compared with RA. Arrows highlight expression at developing septal tips ( $\mathbf{0}$ and $\left.\mathbf{Q}\right)$. R: Western analysis of phosphorylated Smad2 levels in P2 to P14 lungs reveals TGF- $\beta$ canonical Smad signaling is subsequently elevated in P14 $85 \% 0_{2}$ exposed lungs (asterisk). Data are represented as means \pm SEM $(\mathbf{A}-\mathbf{C}, \mathbf{E}$, and $\mathbf{R}) . N=4$ lungs from separate animals per group per time point $(\mathbf{A}-\mathbf{R}) .{ }^{*} P<0.05$ by $t$-test (RA versus hyperoxia at each time point; $\mathbf{A}-\mathbf{C}, \mathbf{E}$, and $\mathbf{R})$. Scale bars: $50 \mu \mathrm{m}(\mathbf{F}, \mathbf{G}, \mathbf{N}$, and $\mathbf{P}) ; 10 \mu \mathrm{m}(\mathbf{0})$. Original magnifications: $\times 10(\mathbf{N}$ and $\mathbf{P}) ; \times 40(\mathbf{0}$ and $\mathbf{Q})$. GAPDH, glyceraldehyde-3-phosphate dehydrogenase.

detectable, Tgf $\beta 3$ expression remained low relative to the others throughout early postnatal distal lung development. Significantly, when compared with RA $\left(21 \% \mathrm{O}_{2}\right)$ controls, $85 \% \mathrm{O}_{2}$ exposure from birth to $\mathrm{P} 4$ (an exposure capable of inhibiting adult alveolar development) resulted in a statistically significant (approximately 50\%) reduction in all three TGF- $\beta$ ligands (Figure 1B). To assess the levels of intracellular TGF$\beta$ signaling, we used Western blots to quantify the levels of the TGF- $\beta$ signaling transducers phospho (p) Smad 2 and pSmad3 proteins compared with total Smad2,3 levels. Although the pSmad2:total-Smad2,3 ratio was not statistically affected, by
P4 hyperoxia significantly reduced the pSmad3:total-Smad2,3 ratio, indicating that $\mathrm{pSmad} 3$-mediated intracellular TGF- $\beta$ signaling is statistically suppressed at these early stages by $85 \% \mathrm{O}_{2}$ exposure (Figure 1, C and D).

Moreover, to examine the broader extent of suppressed TGF- $\beta$ signaling and identify TGF- $\beta$ - pathway downstream targets that are altered by hyperoxia, we used expression profiling in RA and hyperoxia-exposed P4 lungs. Quantitative PCR using a custom array of 84 genes related to TGF- $\beta /$ bone morphogenetic protein-mediated signal transduction, including SMAD, SMAD target genes, adhesion, and 


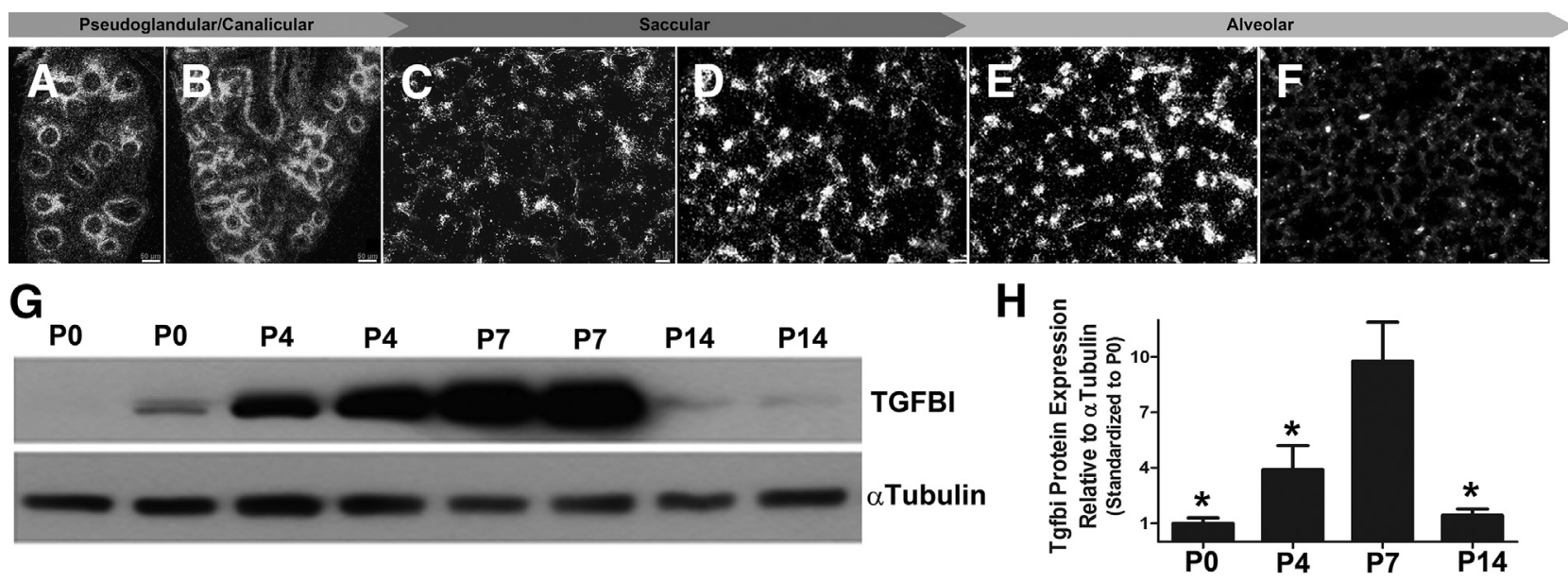

Figure 2 Expression of transforming growth factor- $\beta$-induced matricellular protein (TGFBI) during lung development. A-F: In situ hybridization analysis of Tgfbi spatiotemporal mRNA expression in distal lung sections throughout the pseudoglandular (E15; A), canalicular (E17; B), saccular [postnatal day (P) 0 (C) and P4 (D)], and alveolar [P7 (E) and P14 (F)] stages of lung development. Note widespread Tgfbi expression by discrete cells throughout the saccular and alveolar walls that peaks P4 to P7 but is dramatically reduced by P14. G: Representative immunoblot of duplicate lung TGFBI protein expression (top panel) from P0, P4, P7, and P14 whole lung homogenates with $\alpha$-tubulin loading control (bottom panel). H: Densitometry quantification confirms peak lung TGFBI expression coincides with alveolar-septal development at P4 to P7, followed by significant down-regulation by P14. Densitometry normalized with $\alpha$-tubulin. ${ }^{*} P<0.05$ versus P7, by one-way analysis of variance with Tukey's post test. $N=4$ lungs per group (A-H). Scale bars: $50 \mu \mathrm{m}(\mathbf{A}$ and B); $20 \mu \mathrm{m}(\mathbf{C}) ; 10 \mu \mathrm{m}(\mathbf{D}-\mathbf{F})$.

extracellular molecules and transcription factors, revealed significant changes in transcript levels ( $>1.5$-fold) of two downstream signaling products within hyperoxia-exposed lungs (Figure 1E), namely $T g f b i$ and follistatin $(F s t)$. Fst was significantly up-regulated at P4 (Figure 1E) and is not thought to be normally expressed within the neonatal lung; it is inhibinactivin responsive, and its primary function is the binding and bioneutralization of members of the TGF- $\beta$ superfamily. ${ }^{31}$ Reciprocally, TGF- $\beta$-induced Tgfbi mRNA levels were down-regulated by $>50 \%$ at P4 (Figure 1E). However, both Tgfbi and Fst levels were elevated at P14 in response to hyperoxia (Figure 1E), confirming previous reports of upregulated TGF- $\beta$ levels during the subsequent fibrotic response to neonatal hyperoxia. ${ }^{14,32}$ Because Tgf $\beta 2$ was the isoform that predominated during saccular and early alveolar development (Figure 1A), and Tgfbi was the most significantly and persistently misexpressed TGF- $\beta$ product during that time, we performed detailed analysis of Tgf $\beta 2$ and Tgfbi spatiotemporal expression (Figure 1, F-M). In situ hybridization of distal lung tissue at $\mathrm{P} 4$ demonstrated widespread $T g f \beta 2$ and $T g f b i$ expression concentrated in the developing septal tips (Figure 1, J and $\mathrm{K}$ ), and continuous hyperoxia significantly down-regulated expression of both genes at $\mathrm{P} 4$ within developing septal tips (Figure 1, F and G). Confirming the qPCR data (Figure 1E) and similar to previous reports of increased TGF- $\beta$ signaling in response to chronic neonatal hyperoxia, ${ }^{14,32}$ we found that continuous hyperoxia exposure resulted in subsequent ectopic overexpression of both $T g f \beta 2$ and $T g f b i$ in P14 lungs (Figure 1, $\mathrm{H}$ and I). This is in stark contrast to RA control lungs in which both $T g f \beta 2$ and $T g f b i$ expression had subsided (Figure 1, L and M). Consistent with mRNA data, there was widespread TGFBI matricellular protein expression throughout the distal lung at P4 (Figure 1N), with concentration in the developing septal tips (Figure 1O). Furthermore, hyperoxia significantly down-regulated TGFBI expression in P4-exposed lungs (Figure $1 \mathrm{P}$ ), predominately within the septal tips (Figure 1Q). Because alteration of Tgf- $\beta$ ligand at the mRNA level does not always cause changes in intracellular signal activity, we examined pSmad2 protein levels P2 to P14. In agreement with published data, ${ }^{14,32}$ elevated intracellular TGF- $\beta$ canonical Smad-mediated signaling was evident only with prolonged, continuous, hyperoxia exposure through P14 (Figure 1R). Taken together, hyperoxia acutely diminishes saccular lung TGF- $\beta$ superfamily signaling and misexpression of downstream TGF- $\beta$-responsive targets during early neonatal lung morphogenesis, coincident with physiological alveolar simplification. However, continued hyperoxia exposure results in a biphasic response and subsequent up-regulation of TGF- $\beta$ signaling and downstream responder expression.

\section{TGFBI Spatiotemporal Expression Coincides with Alveolar Septal Development}

Given the close correlation of Tgfbi expression in P4 septal tips and significant down-regulation in response to hyperoxia, we examined Tgfbi mRNA throughout the major stages of lung development. In situ hybridization localized Tgfbi mRNA to the mesenchyme immediately beneath the developing epithelial tubules at embryonic day (E)14.5 during the pseudoglandular period (Figure 2A) and at E16 during the canalicular period (Figure 2B). At birth, in the early postnatal saccular stage, Tgfbi expression was absent from the large airways and concentrated in scattered cells within the developing saccules (Figure 2C). Expression intensified, expanded, and concentrated at developing septal tips during the transition from the saccular to alveolar stage at P4 (Figure 2D) and P7 (Figure 2E). However, in contrast to earlier stages, by P14 when bulk alveolar development is nearly complete, Tgfbi mRNA was largely 


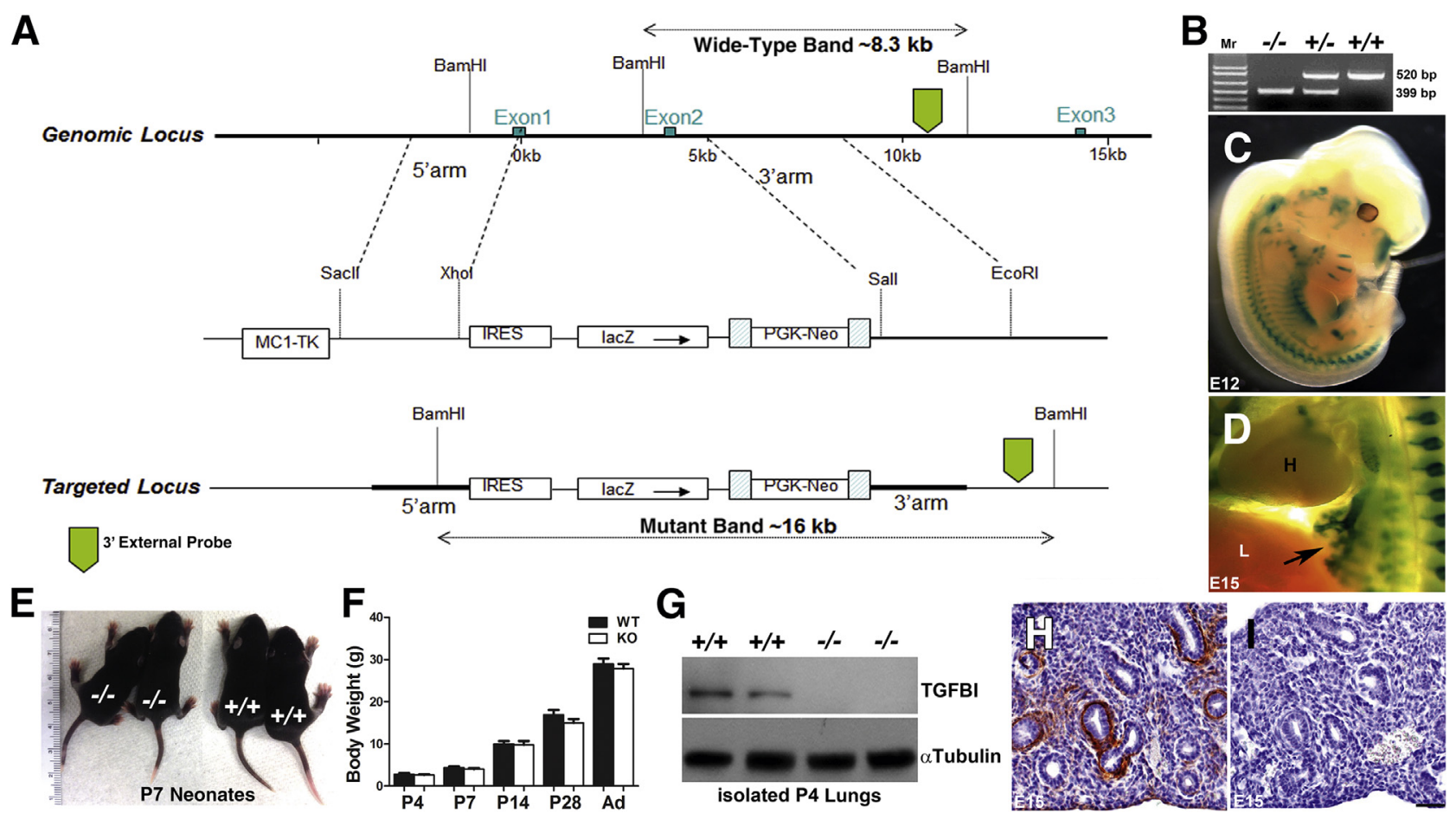

Figure 3 Systemic loss of Tgfbi does not affect postnatal viability. A: Strategy for generation of Tgfbiacz mice. B: PCR genotyping detection of wild-type (WT; top panels) and null TgfbilacZ (bottom panels) alleles in Tgfbi null $(-/-)$, heterozygous $(+/-)$, and WT $(+/+)$ animals. C and D: Whole-mount X-Gal staining demonstrating TgfbilacZ reporter expression in heterozygote E12 (C) and E15 embryos (arrow indicates lacZ within the developing lung buds; D). E and F: Null pups (left panel) are grossly indistinguishable from wild-type pups (right panel) at P7 and exhibit similar growth characteristics from P4 through to adulthood (Ad). G: Western blot analysis verifies the absence of transforming growth factor- $\beta$-induced matricellular protein (TGFBI) from within duplicate null P4 lungs when compared with age-matched WT lungs and $\alpha$-tubulin loading control. $\mathbf{H}$ and I: Immunohistochemical staining for TGFBI in E15 lung sections from WT (H) and null (I) littermate embryos confirms in utero TGFBI absence in nulls. Data are represented as means \pm SEM (F). $N=5$ to 9 animals per group per time point (F). Scale bar $=50 \mu \mathrm{m}(\mathbf{H}$ and $\mathbf{I})$.

undetectable in alveolar regions (Figure 2F) and restricted within the chondrogenic framework around the bronchus and bronchi airways. Whole lung analysis demonstrated peak expression of a single approximately 50-kDa TGFBI protein between $\mathrm{P} 4$ and $\mathrm{P} 7$, which coincides with saccular maturation and bulk alveolar septation (Figure 2, G and H). Western detection of TGFBI expression at P14 was similar to P0 levels and significantly decreased. Thus, peak lung TGFBI expression correlates with maximal alveolar-septal development from P4 to P7 during normal mouse lung morphogenesis, with negligible levels in adult lungs.

\section{Genetic Ablation of Tgfbi Pinpoints TGFBI as a Required Component of Normal Alveolar Structure and Function}

Because both TGFBI spatiotemporal expression pattern and its down-regulation after hyperoxia exposure appeared coincident with alveolar simplification, we hypothesized that Tgfbi is necessary for normal alveolar septal development. To test its requirement in distal lung development, we generated $T g f b i^{\text {lac } Z}$ knockin mice in which TGFBI protein translation was abolished by knocking in a $\beta$-galactosidase reporter and floxed-neo selection cassette to replace the ATG start site, most of exon 1, and all of exon 2 of the Tgfbi allele
(Figure 3A). After Cre-mediated removal of the floxed-neo selection cassette, we found that homozygous null pups were $100 \%$ viable. The $T g f b i^{\text {lacZ }}$ knockout mice are fertile, are indistinguishable from wild-type littermates at $\mathrm{P7}$ (Figure 3E), and continue to have normal growth and outward development through adulthood (Figure 3F). Western blot analysis of neonatal lung homogenates (Figure 3G) and immunohistochemistry (Figure 3, H and I) of Tgfbi-null and wild-type fetal lungs both confirmed the absence of TGFBI protein within $T g f b i^{\text {lacZ/lacZ }}$ knockout (-/-) mutants and generation of a null allele.

Using our $\beta$-galactosidase reporter to map $T g f b i$ gene expression, we confirmed that lac $Z$ expression in heterozygous $T g f b i^{l a c Z}$ animals (Figure 3, A-D) faithfully recapitulated wild-type endogenous $T g f b i$ expression previously observed by in situ hybridization, ${ }^{27}$ especially within the chondrogenic elements of the skeleton and heart. Within the lungs, lacZ expression is initially detected in E13 lung buds, restricted to the developing airways at E15 (Figure 3D) and E17 (Figure 4A), widespread throughout the peripheral lung at P7 (Figure 4B), but confined to chondrogenic cells around the mature airways and absent from the peripheral airspaces from P14 onward (Figure 4C). Although lacZ expression was similar in both heterozygotes and homozygous Tgfbinull lungs at E17 (Figure 4, A and D) and P7 (Figure 4, B 


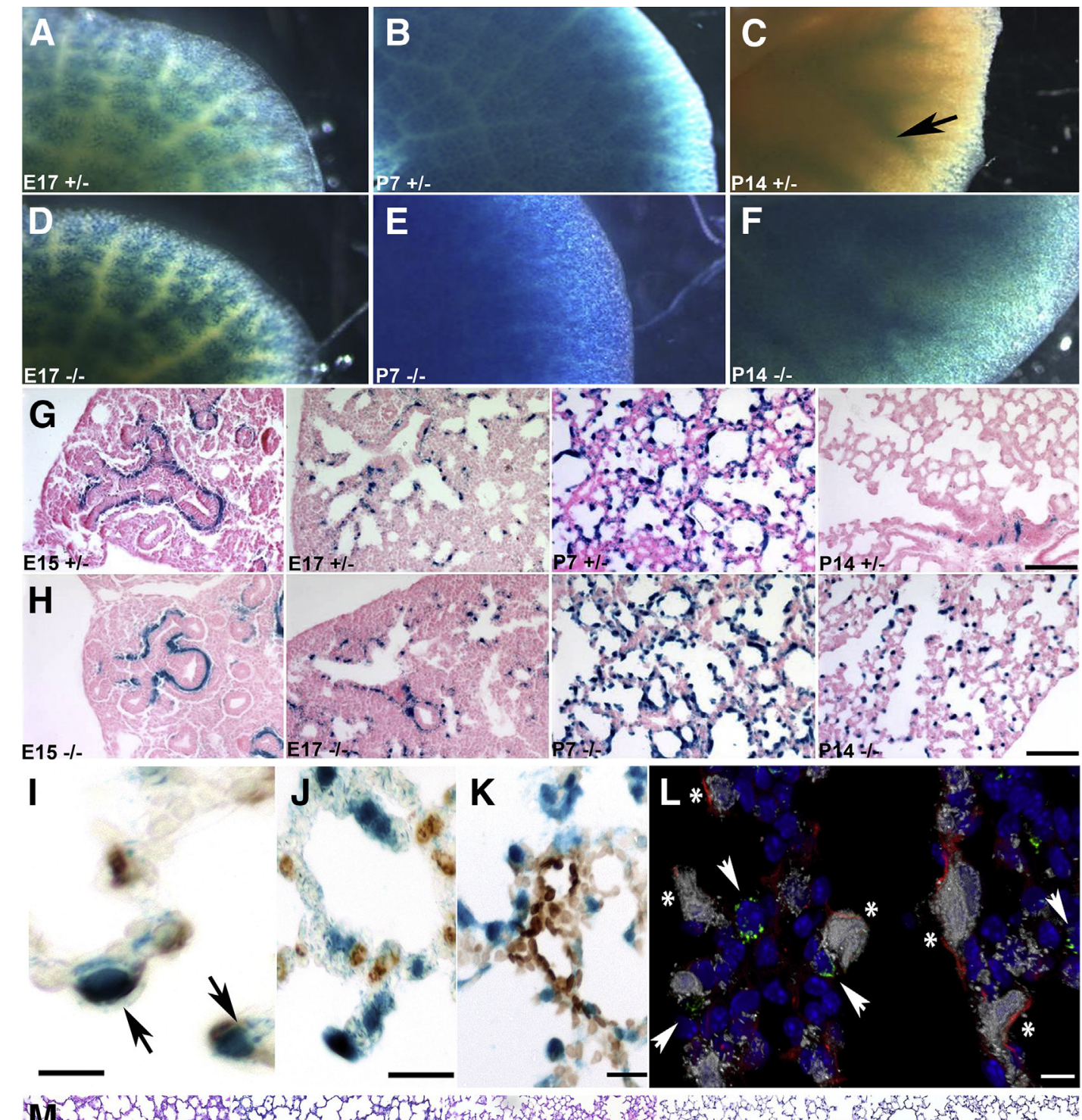

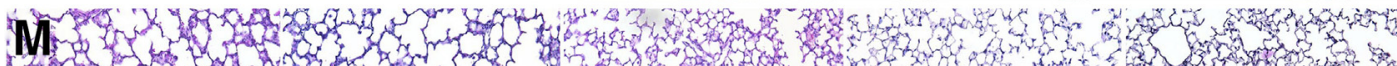

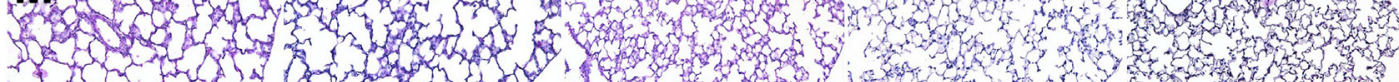

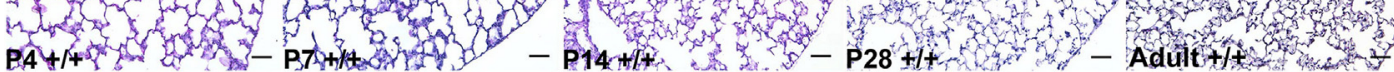

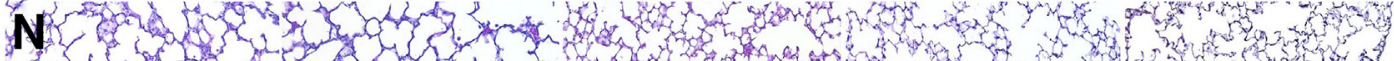

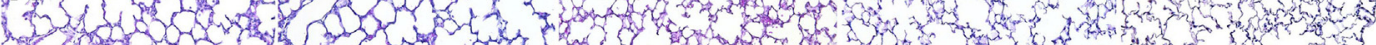

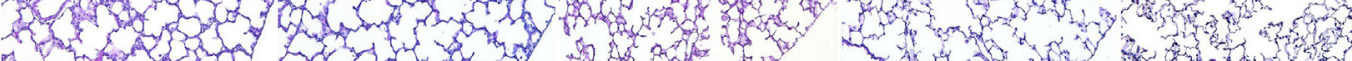

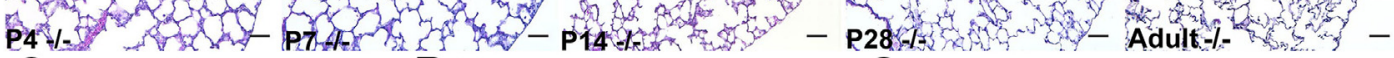

0

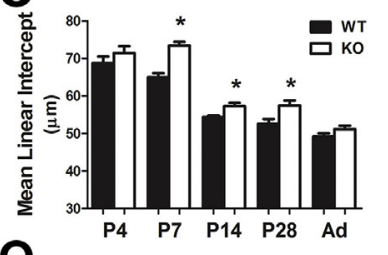

Q

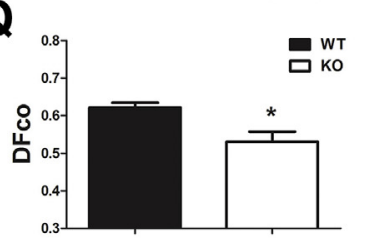

P

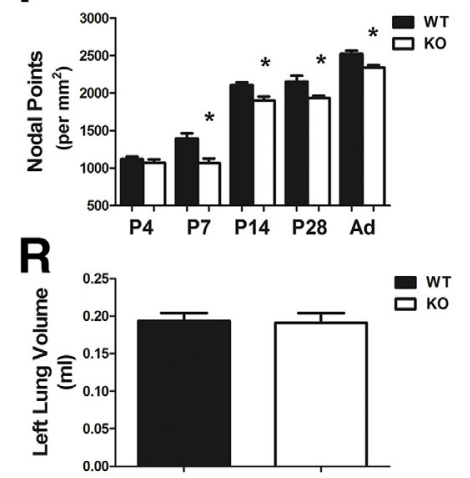

S

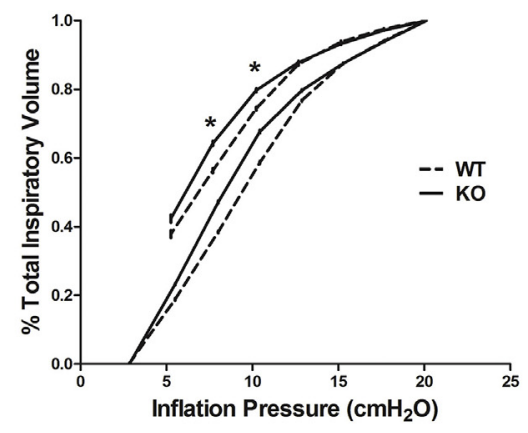


and E), P14 null lungs exhibited ectopic, persistent expression in the peripheral distal lung (Figure 4F). Closer examination of cellular localization with control heterozygous lacZ-stained lung sections indicated that at E15, expression was absent from both the mesenchymal cells surrounding the terminal tubules and the peripheral mesenchyme, but confined to a band of mesenchymal cells immediately beneath the proximal epithelial tubules (Figure 4G). There was progressive expansion of cells away from the control large airways and into single cells in the surrounding mesenchyme from E17, with widespread expression concentrated in the septal tips at P7 (Figure 4G). Cellular localization of $l a c Z$ in homozygous null $T g f b i^{l a c Z}$ lungs was similar to that of heterozygotes from E15 to P7 (Figure $4 \mathrm{H}$ ), but differed at P14 in that expression persisted in discrete cells within the septal tips (Figure $4 \mathrm{H}$ ). The ectopic pattern of staining was reminiscent of the persistence of $\alpha-\mathrm{SMA}^{+}$myofibroblasts previously observed in response to chronic hyperoxia. ${ }^{22}$ Costaining of $T g f b i^{\text {lac } Z}$ lung sections with $\alpha$-SMA (Figure $4 \mathrm{I}$ ), surfactant protein-C (Figure 4J), and platelet endothelial cell adhesion molecule (Figure $4 \mathrm{~K}$ ) antibodies revealed that most lac $^{+}$cells were $\alpha$-SMA ${ }^{+}$(Figure $4 \mathrm{I}$ ), indicating that Tgfbi-expressing cells are $\alpha$-SMA ${ }^{+}$myofibroblasts and not alveolar type II cells. Confocal coimmunofluorescence staining confirmed that $\alpha$ SMA is tightly associated with $T g f b l^{\text {lacZ }}$-expressing cells (Figure $4 \mathrm{~L}$ ), indicating that TGFBI is expressed within the myofibroblast lineage. Furthermore, single-cell analysis of E18.5 lungs supports our data that the predominant cell type expressing Tgfbi is the myofibroblast. ${ }^{33}$

To determine the role of $T g f b i$ in conducting airway development and alveolar septation, we examined Clara cell secretory protein expression and measured distal airspace size (via mean linear intercept) and complexity (via nodal point density) throughout alveolar development. Clara cell secretory protein mRNA was equally expressed within columnar epithelial cells lining E17, P4, and P7 wild-type and null bronchi/bronchioles. Similarly, gross comparison of in utero wild-type and null lungs did not reveal any differences. Moreover, no differences between heterozygote and wild-type lungs were observed by histological analysis or by the analyses of specific markers described below. However, representative lung sections from wild-type (Figure 4M) and Tgfbi-null (Figure $4 \mathrm{~N}$ ) mice indicated that, although saccular structure was similar at P4, loss of Tgfbi resulted in persistent distal airspace simplification from P7 onward (Figure 4, M and N). The terminal air sacs are subdivided into smaller units via alveolarization in wild types, but in Tgfbi nulls, alveolar airspace enlargement was evident from P7 to P28, but normalized in 12-month adult lungs (Figure $4 \mathrm{O}$ and Table 1). However, Tgfbi-null nodal density, a measure of distal airspace complexity, was decreased from P7 through to adulthood (Figure 4P and Table 1). Significantly, although the persistent structural differences in airspace complexity were of small magnitude, functional analysis of gas exchange, via measurement of the DFco, indicated that adult lungs lacking $T g f b i$ have a significant decrease in gas exchange efficiency (Figure 4Q). In addition, although total lung volume was similar in both wild-type and $T g f b i$ knockouts (Figure 4R), lungs of $T g f b i$ nulls displayed diminished elastic recoil (Figure 4S). Thus, although Tgfbi is neither required for in utero lung development nor lung airway morphogenesis, it is necessary for normal neonatal lung saccular remodeling, specifically during the initial alveolar septation stage. Moreover, $T g f b i$ is also required for subsequent normal lung elastic properties and gas exchange function.

\section{Structural Analysis of Tgfbi-Null Lungs Suggests Normal Vascular Development but Ectopic Localization of Key Matrix Proteins}

To begin to realize the mechanisms underlying abnormal alveolar development in Tgfbi nulls, we examined key mesenchymal components known to be vital for alveolar septation, including elastin deposition, ${ }^{16}$ vascular development, ${ }^{34}$ and $\alpha$-SMA ${ }^{+}-$myofibroblast localization. ${ }^{35-37}$ At P7, when elastin is normally located in the tips of developing alveolar septa in wild-type animals (Figure 5A), in Tgfbi nulls, elastin formed bands within the alveolar walls and there was a lack of elastin $^{+}$tips (Figure 5B). Because qPCR analysis of elastin mRNA levels did not reveal any alteration in P4 or P7 null lungs, the reduction of elastin deposition at the septal tips most likely represents either a defect in microfibril formation or a deficiency in other accessory proteins required for elastin fiber assembly. As screened by staining for the endothelial marker,

Figure 4 Phenotypic analysis of Tgfbi knockout (KO) lungs. A-F: Whole-mount X-Gal staining indicating TgfbilacZ reporter expression in heterozygous (+/-) lungs at E17 (A), postnatal day (P) 7 (B), and P14 (arrow indicates lacZ restricted around large airways; C) compared with TgfbilacZ nulls (-/-) at E17 (D) and P7 (E) and P14 (F). F: Although there is similar lacZ spatiotemporal expression at E17 and P7, there is widespread ectopic lacZ reporter expression within the P14-null distal airspaces. $\mathbf{G}$ and $\mathbf{H}$ : Histological analysis confirms above whole-mount reporter patterns and ectopic Tgfbi ${ }^{\text {lacZ }}$ expression in developing septal tips of P14 nulls (H) compared with heterozygous controls (G). I-K: Immunohistochemical analysis of X-Gal-stained sections demonstrates colocalization of $\alpha$-smooth muscle actin ( $\alpha$ SMA) protein (I, marker of alveolar myofibroblasts) with TgfbilacZ -expressing cells (arrows) but not with Pro-SPC (marker of alveolar type II cells; J) or platelet endothelial cell adhesion molecule (PECAM) marker (K). L: Confocal coimmunolocalization of TGFBI-driven lacZ (gray) with $\alpha$-SMA (red), Pro-SPC (green), and nuclear DAPI (blue) markers. There is colocalization of lacZ with $\alpha$-SMA (asterisk), but not with Pro-SPC (arrowheads). M and N: Hematoxylin and eosin-stained inflationfixed lung sections throughout alveolar lung development in wild-type (M) and Tgfbi nulls (N) from P4 through 12 months/adulthood (Ad). $\mathbf{0}$ and P: Quantification of distal airspace development of sections in $\mathbf{M}$ and $\mathbf{N}$ via mean linear intercept $\mathbf{( 0 )}$ and nodal point density $(\mathbf{P})$ in wild-type (WT) and Tgfbi nulls reveals that during the period of rapid alveolar septation, loss of Tgfbi retards alveolar septation, resulting in larger and/or simpler distal airspaces from P7 onwards. Q: Functional analysis by way of measurement of the diffusing factor for carbon monoxide (DFco) in adult WT and Tgfbi nulls reveals a persistent functional insufficiency. R: However, left lung volume, as assessed by water displacement in adult WT and Tgfbi nulls, is equivalent. S: Assessment of lung elastance by pressure-volume loops in adult WT (broken line) and Tgfbi nulls (solid line) confirms nulls exhibit decreased elastic recoil. Data are represented as means \pm SEM ( $\mathbf{0}-\mathbf{R}) . N=4$ to 9 separate animals per group per time point (A-S). ${ }^{*} P<0.05$ by $t$-test (WT versus Tgfbi null at each time point). Scale bars: $50 \mu \mathrm{m}(\mathbf{G}, \mathbf{H}, \mathbf{M}$, and $\mathbf{N}) ; 5 \mu \mathrm{m}(\mathbf{I}$ and $\mathbf{L}) ; 10 \mu \mathrm{m}(\mathbf{J}) ; 20 \mu \mathrm{m}(\mathbf{K})$. 
Table 1 Growth and Distal Lung Development in the Presence and Absence of Tgfbi

\begin{tabular}{lrll}
\hline $\begin{array}{l}\text { Postnatal } \\
\text { age }(N)\end{array}$ & Weight $(\mathrm{g})$ & MLI $(\mu \mathrm{m})$ & $\begin{array}{l}\text { Nodal density } \\
\text { (points per } \mathrm{mm}^{2} \text { ) }\end{array}$ \\
\hline P4-WT (6) & $2.8 \pm 0.3$ & $68.82 \pm 1.70$ & $1120 \pm 35$ \\
P4-K0 (5) & $2.6 \pm 0.2$ & $71.49 \pm 1.80$ & $1069 \pm 46$ \\
P7-WT (6) & $4.4 \pm 0.3$ & $65.03 \pm 1.07$ & $1393 \pm 69$ \\
P7-K0 (5) & $4.0 \pm 0.3$ & $73.46 \pm 0.98^{*}$ & $1066 \pm 61^{*}$ \\
P14-WT (7) & $10.0 \pm 0.7$ & $54.40 \pm 0.40$ & $2105 \pm 39$ \\
P14-K0 (8) & $9.7 \pm 1.0$ & $57.28 \pm 0.91^{*}$ & $1898 \pm 56^{*}$ \\
P28-WT (7) & $16.9 \pm 1.2$ & $52.61 \pm 1.24$ & $2153 \pm 77$ \\
P28-K0 (6) & $14.9 \pm 0.9$ & $57.47 \pm 1.33^{*}$ & $1932 \pm 30^{*}$ \\
Ad-WT (4) & $29.9 \pm 0.3$ & $49.22 \pm 0.87$ & $2522 \pm 41$ \\
Ad-K0 (4) & $29.2 \pm 1.7$ & $51.17 \pm 0.95$ & $2339 \pm 33^{*}$ \\
\hline
\end{tabular}

Values are means \pm SEM.

${ }^{*} P<0.05$ versus $W T$ at equivalent postnatal age.

KO, knockout; MLI, mean linear intercept; WT, wild-type littermate.

von Willebrand factor, normal vascular development was maintained in Tgfbi-null lungs (Figure 5, C and D). Although $\alpha$ SMA was widely expressed at P7 in both groups, the intensity of $\alpha$-SMA staining was modestly increased in Tgfbi nulls and localization of $\alpha$-SMA protein within the alveolar septa was not consistently at the tips (Figure 5, E and F). Notably, at P14, when $\alpha$-SMA protein expression is typically absent from the alveolar walls, Tgfbi-null lungs had persistence of alveolar $\alpha$ $\mathrm{SMA}^{+}-$myofibroblasts (Figure 5, G and $\mathrm{H}$ ). Likewise, Western blot analysis confirmed $\alpha$-SMA protein levels were significantly elevated within both P7 and P14 null lungs (Figure 5I).

Coincident with the first indication of diminished alveolar septation (Figure 4, M-P), Tgfbi-null lungs had statistically significant reduced cellularity at P4 and P7 (Figure 5J), which may be explained partly by a reduced proliferation index in null distal lung cells at P4 (Figure 5K). At P14, $T g f b i$ nulls displayed similar cellularity (Figure $5 \mathrm{~J}$ ) in association with a statistically significantly increased null proliferation index (Figure 5K). Because terminal deoxynucleotidyl transferase-mediated dUTP nick-end labeling staining at P4, P7, or P14 did not detect any up-regulation within null lungs compared with wild type, this suggests that a transient reduction of proliferation likely accounts for the observed declining differences in airspace size as the $T g f b i$-null lungs mature into adulthood. Transmission electron microscopy of septal tips in wild-type (Figure 5, L and $\mathrm{M}$ ) and Tgfbi-null (Figure 5, N and $\mathrm{O}$ ) lungs indicated that key ultrastructural components, including collagen microfilaments and elastin (present as both amorphous elastin and microfibrils), were present in wild-type and null septa but that elastin staining was diminished at tips of stunted null septa (Figure $5 \mathrm{~N}$ ). Moreover, the septal tips of Tgfbi-null lungs lacked myofibroblasts, because the myofibroblast nuclei were instead mostly localized to the bases of underdeveloped Tgfbi-null septa (Figure $5 \mathrm{~N}$ ). Combined with the histomorphometric results (Figure 4) and the spatiotemporal expression of TGFBI (Figure 3), these structural data indicate that the absence of $T g f b i$ results in diminished alveolar septation and interference with normal septal tip reorganization that is necessary during secondary septa morphogenesis.

Genetic Loss of Tgfbi Results in an Imbalance of Lung Fibroblast Populations during a Critical Period of Alveolar Septal Development

Expansion via proliferation and spreading of platelet-derived growth factor receptor (PDGFR) $\alpha^{+}$mesenchymal progenitor cells to the distal airspaces is essential for alveolar septal growth. ${ }^{35-38}$ Given the diminished proliferation and alveolar septation observed, as well as the diminished elastin and mislocalization of $\alpha$-SMA in Tgfbi-null lungs, we examined Pdgfr $\alpha$ expression (Figure 6, A-D). At P4, when distal airspace development was similar to wild types, $T g f b i$-null lungs displayed normal expression of Pdgfr $\alpha$ mRNA (Figure 6, A and C). However, unlike wild-type lungs, which continued to have widespread Pdgfr $\alpha$ expression (Figure 6B), P7 Tgfbi nulls exhibited a paucity of $\mathrm{Pdgfr}^{+}$cells (Figure 6D) coincident with distal airspace simplification (Figure 4, M-P). Using the same targeted TGF- $\beta$-signaling array that identified $T g f b i$ as being significantly downregulated by hyperoxia (Figure 1), two other components of TGF- $\beta$ signaling, follistatin and serpine 1 , were found to be up-regulated in P7 Tgfbi isolated lungs when compared with age-matched control littermate lungs. More important, Fst and Serpinel are associated with abnormal maturation and reduced proliferation of lung fibroblasts, ${ }^{26,39}$ both of which we observed in developing Tgfbi-null lungs. At P7, striking up-regulation and ectopic expression of FST protein were observed within the alveolar septa of Tgfbi-null lungs (Figure 6G) when compared to wild type (Figure 6E), and Fst was also found to be up-regulated in response to physiological hyperoxia-mediated alveolar inhibition (Figure 1E), suggesting that this negative regulator of TGF- $\beta$ signaling may play a conserved role within both physiological and genetic mouse models of neonatal chronic lung disease. Although not as robust, serpine $1 \mathrm{mRNA}$ was also up-regulated and ectopically expressed in P7 Tgfbi-null lungs (Figure 6H), when compared to wild type (Figure 6F). Thus, inhibition of alveolar septation and mislocalization of $\alpha$-SMA/elastin in Tgfbi-null lungs are associated with decreased lung proliferation and misexpression of TGF- $\beta$-pathway genes related to lung fibroblast development. Moreover, this imbalance within alveolar septal fibroblast populations may underlie the observed decreased adult lung elastic recoil and poor gas exchange function.

\section{Discussion}

Initial Postnatal TGF- $\beta$ Signaling Suppression Contributes to BPD Pathogenesis in Mice

Human saccular maturation, vital for establishment of postnatal distal lung complexity, is designed to occur in the protected, low-oxygen, uterine environment. Although 

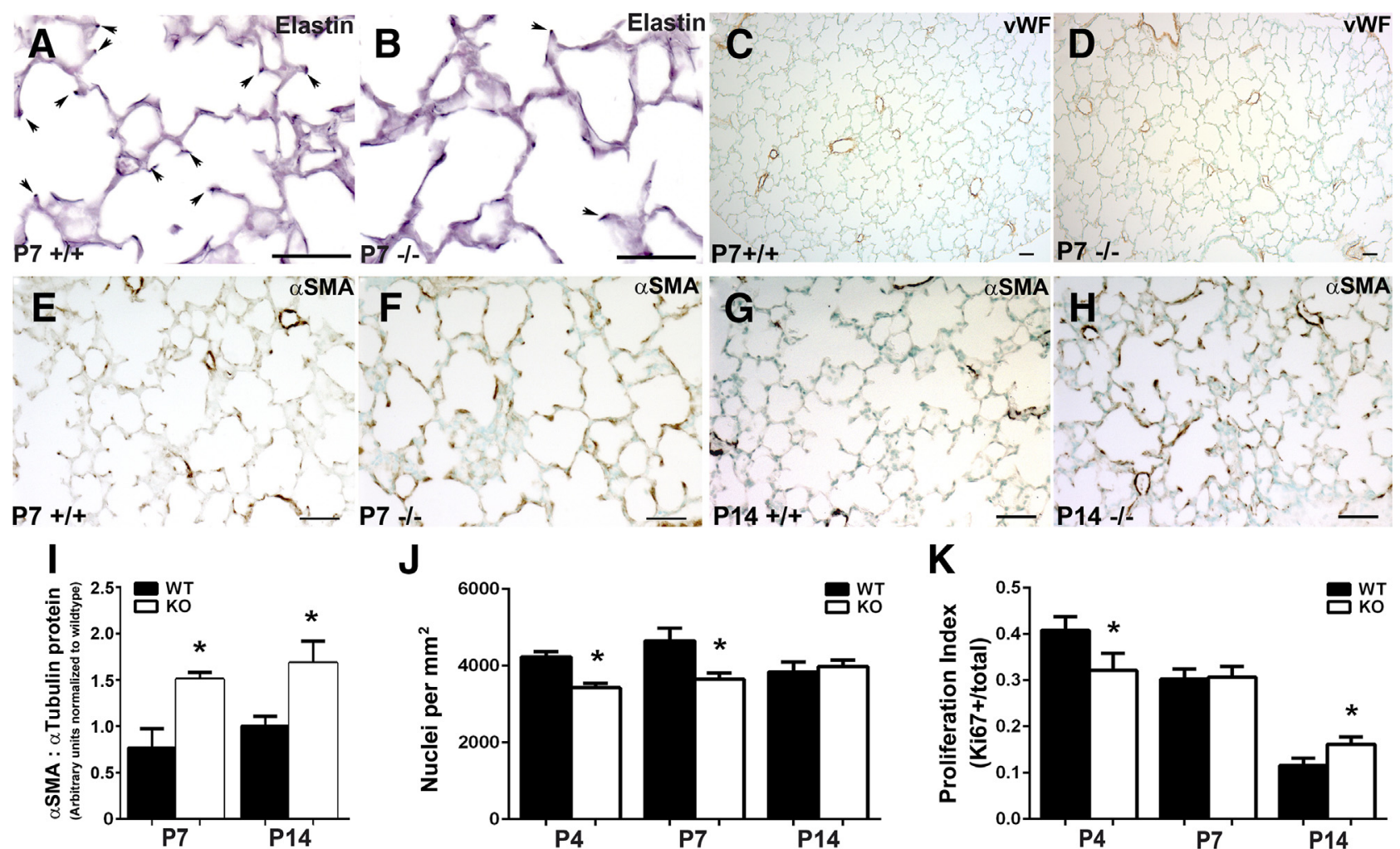

$\mathbf{J}$

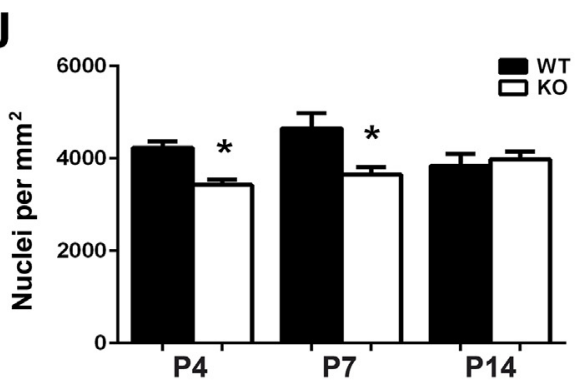

K
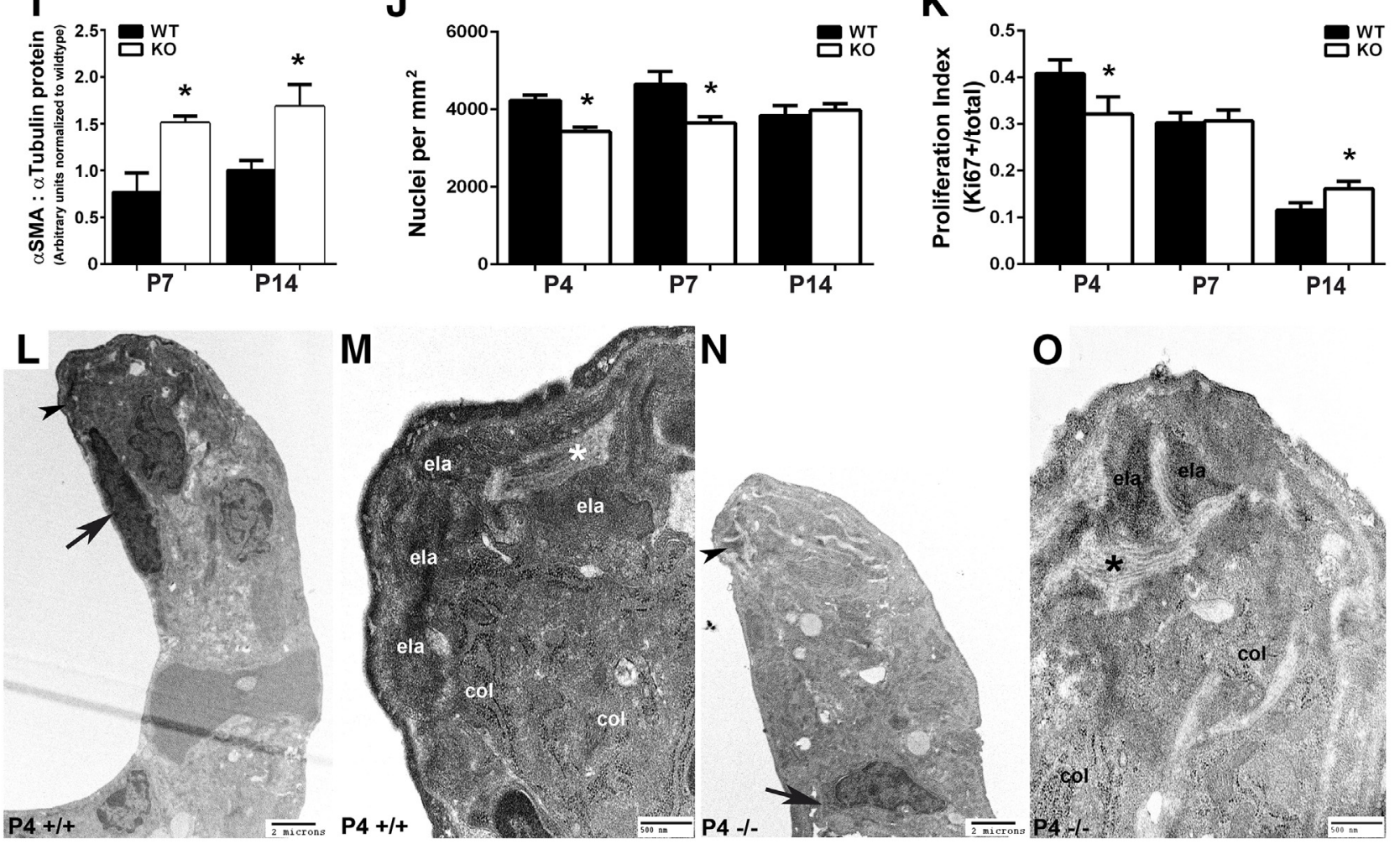

Figure 5 Structural and ultrastructural examination of neonatal lung alveolar septation defects in Tgfbi-null mice. A-F: Immunohistochemical analysis of elastin (A and B), von Willebrand factor (vWF; $\mathbf{C}$ and $\mathbf{D})$ ), and $\alpha$-smooth muscle actin $(\alpha-S M A ; \mathbf{E}$ and $\mathbf{F})$ localization in postnatal day (P) 7 wild-type (WT; +/+) and Tgfbi null (-/-) lungs. There is a significant lack of elastin-positive P7 null tips (septal tips indicated via arrows in $\mathbf{A}+/+$ and B - /-), but vWF and $\alpha$-SMA are similarly distributed in WT (C and E) and null (D and F) P7 tips. $\mathbf{G}$ and $\mathbf{H}$ : Compared with WT animals (G), there is ectopic expression of $\alpha$-SMA protein in alveolar septal tips of P14 Tgfbi nulls (H). I: Western verification of elevated $\alpha$-SMA levels in P7 and P14 Tgfbi null lungs. J and K: Assessment of alveolar tissue cellularity (J) and proliferation index (K) in WT and Tgfbi nulls at P4, P7, and P14. L-0: Transmission electron micrographs of septal tips at P4 in WT ( $\mathbf{L}$, enlarged in $\mathbf{M}$ ) and Tgfbi null ( $\mathbf{N}$, enlarged in $\mathbf{0}$ ) lungs. Normal collections of collagen microfilaments (col) and parallel collagen bundles (asterisk) are observed within both WT and blunted Tgfbi null septal tips; however, amorphous elastin (ela) deposition is diminished in stunted Tgfbi null septal tips ( $\mathbf{N}$, arrowhead) when compared with WT (L, arrowhead). Data are represented as means \pm SEM (I-K). $N=5$ to 6 separate animals per group per time point $(\mathbf{A}-\mathbf{0}) .{ }^{\star} P<0.05$ by $t$-test (WT versus Tgfbi null at each time point). Scale bars: $50 \mu \mathrm{m}(\mathbf{A}-\mathbf{H}) ; 2 \mu \mathrm{m}$ ( $\mathbf{K}$ and $\mathbf{M}) ; 500 \mathrm{~nm}$ ( $\mathbf{L}$ and $\mathbf{N})$. K0, knockout.

little is known about the factors that control it, the process of saccular maturation is likely complex and dependent on intricate molecular networks that establish and orchestrate timely remodeling of lung structure and function in vivo. Although essential for life, prematurely exposing the immature lung to relative hyperoxia clearly inhibits saccular lung development and secondary septation by uncoupling normal molecular pathways. ${ }^{6,7,10}$ Significantly, TGF- $\beta$ signaling is one of the key growth factor conduits known to influence injury, mesenchymal 

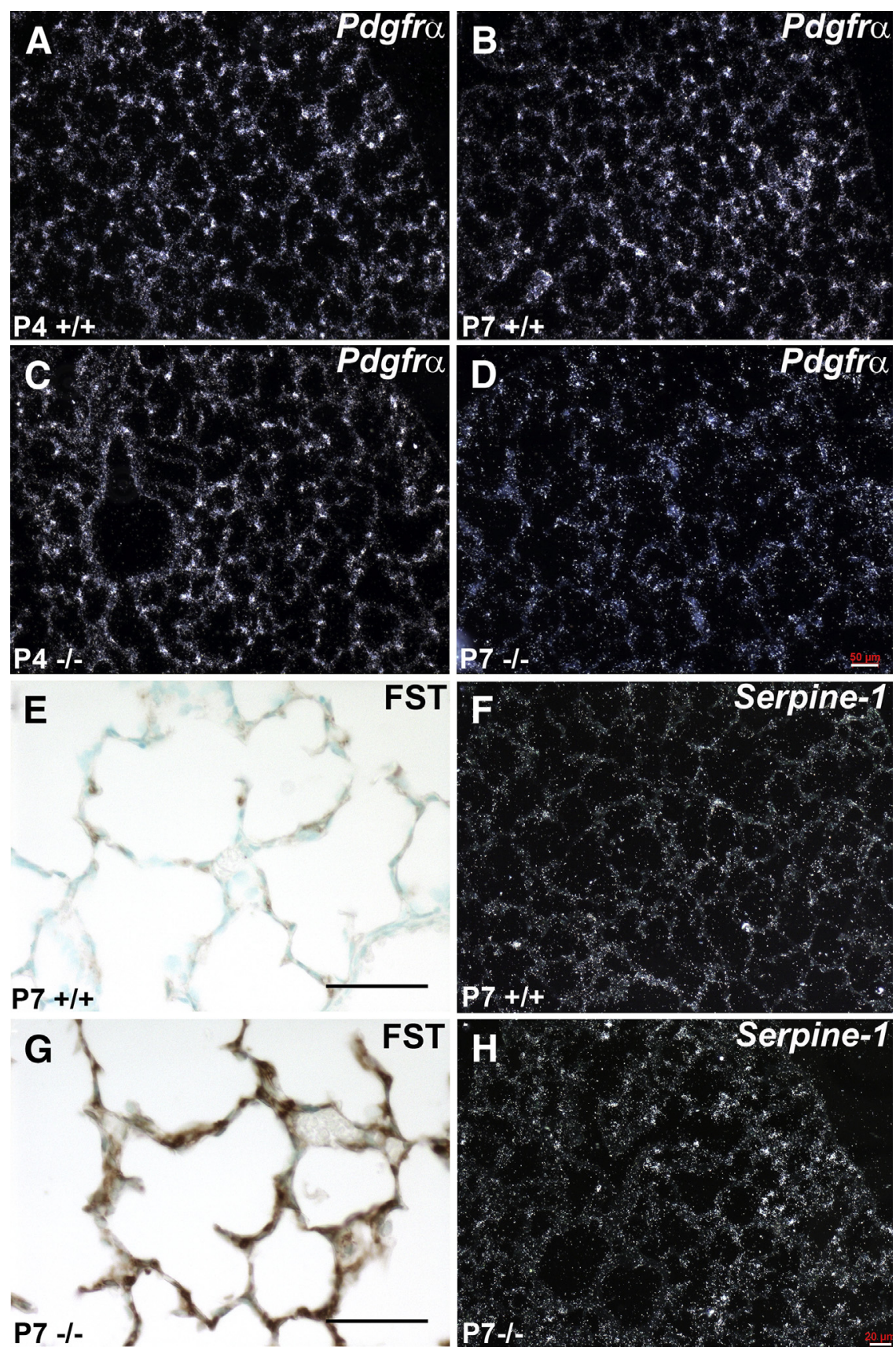

Figure 6 Dynamic expression deviations in myofibroblast progenitor and downstream transforming growth factor (TGF)- $\beta$ family signaling markers in Tgfbi null lungs during alveolar septal development. A-D: In situ hybridization detection of platelet-derived growth factor receptor $\alpha$ (Pdgfr $\alpha$ ) mRNA expression in developing alveoli in wild-type (A and B) and Tgfbi nulls (C and D), at postnatal day (P) 4 and P7, reveals suppression of Pdgfra in P7 null lungs. $\mathbf{E}$ and $\mathbf{G}$ : Immunohistochemical localization of follistatin (FST) protein within P7 wild-type (E) and Tgfbi-null (G) lungs indicates excessive FST deposition in null alveoli. $\mathbf{F}$ and $\mathbf{H}$ : In situ hybridization of serpine mRNA expression in developing alveoli in P7 wild-type (F) and Tgfbi-null (H) detects up-regulation within the null lung periphery. Scale bars: $50 \mu \mathrm{m}(\mathbf{A}-\mathbf{F}) ; 20 \mu \mathrm{m}$ (G and $\mathbf{H})$. homeostasis, and lung development. ${ }^{4,5,7,10}$ Although mechanically ventilated preterm infants with developing lung disease have elevated TGF- $\beta$ levels in tracheal aspirates, ${ }^{40,41}$ animal studies linking altered TGF- $\beta$ signaling to arrested alveolar development are conflicted. Chronic hyperoxia impairs secondary septation and results in alveolar simplification associated with up-regulation of TGF- $\beta .^{14,32,42,43}$ However, although most models associate elevated signaling after chronic exposure to moderate $(85 \%)$ or severe $(>95 \%)$ oxygen well into the alveolar stage, ${ }^{14,32,42,43}$ they may not accurately recapitulate the human condition, which is associated with relatively brief exposure to modest hyperoxia during the more sensitive saccular and early alveolar stages. Forced expression of ectopic TGF- $\beta 1$ in postnatal mice throughout saccular and alveolar development inhibits alveolarization, but with significantly more fibrosis and inflammation than that seen in other models of inhibited alveolar septation. ${ }^{43-45}$ On the basis of these data, many have speculated that excessive TGF- $\beta$ disrupts septation and should be targeted as a therapy to promote alveolarization. ${ }^{32,43}$ However, inhibiting TGF- $\beta$ during development via genetic ablation of the Tgf $\beta$-II receptor, ${ }^{46} \operatorname{Smad} 3,{ }^{47}$ or latent TGF- $\beta$ binding proteins $3 / 4^{48,49}$ results in normal lungs at birth, followed by a subsequent age-related increase in the size of alveolar spaces, challenging the assumption that TGF- $\beta$ 
up-regulation is a primary effector inhibiting initial alveolar septation.

We previously demonstrated that the TGF- $\beta$-responsive matricellular protein, periostin, is an early marker of inhibited neonatal murine lung alveolar septation, because its deposition is acutely suppressed via hyperoxia before subsequent up-regulation coincident with fibrosis. ${ }^{22}$ Herein, we show mRNA and protein levels of the paralogous ${ }^{26}$ TGF- $\beta$-responsive matricellular protein, TGFBI, are similarly down-regulated and then subsequently up-regulated in response to hyperoxia exposure from birth. Moreover, we found that Tgf $\beta 2$ mRNA and pSmad3 TGF- $\beta$ canonical intracellular mediator protein levels are acutely suppressed in response to hyperoxia, before subsequent up-regulation during the onset of ensuing fibrosis. Thus, contrary to the prevailing paradigm suggesting excessive TGF- $\beta$ activation is a primary effector of BPD pathogenesis, our genetic and physiological data both indicate that at multiple levels during a period of postnatal lung development critical to eventual alveolar structure and function, TGF- $\beta$ ligands, intracellular mediators, and downstream TGF- $\beta$-responsive ECM effector targets all appear to be suppressed initially coincident with arrested alveolar septation. Although all three TGF- $\beta$ ligands serve overlapping roles, the ligandspecific knockout phenotypes suggest each has unique functions within the developing lung. Deletion of $\operatorname{Tgf} \beta 1$ does not affect alveolar septation, ${ }^{50}$ but overexpression of TGF $\beta 1$ is considered to be an inhibitor of surfactant expression $^{51}$ and embryonic lung branching morphogenesis in vivo and in vitro. ${ }^{52} \operatorname{Tgf} \beta 3$ deletion arrests maturation of the canalicular lung, ${ }^{53}$ but it is not normally expressed during postnatal saccular remodeling. In agreement with published data, ${ }^{54}$ we have shown that $\operatorname{Tgf} \beta 2$ expression peaks during saccular development. However, although it is the major ligand required for in utero branching, ${ }^{55} \mathrm{Tgf} \beta 2$ knockouts die shortly after birth, with severe cyanosis and collapsed terminal airways, ${ }^{56}$ hindering efforts to determine its precise function during postnatal saccular and alveolar maturation. Significantly, although these studies were not specifically designed to examine hyperoxia-mediated suppression of TGF- $\beta$ ligand expression but rather effects on downstream TGF- $\beta$ effectors, our data show that hyperoxia down-regulates $\operatorname{Tgf} \beta 2$ coincident with an arrest of saccular maturation. Together, these findings support a mechanism whereby loss of TGF $\beta 2$ specifically inhibits saccular morphogenesis via down-regulation of intracellular $\mathrm{pSmad} 2 / 3$ mediators and consequent lack of TGF- $\beta$-induced ECM effector expression. Thus, we speculate that initial suppression of Tgf $\beta 2$ may contribute to BPD pathogenesis. Consequently, in agreement with published $\operatorname{Smad} 3$ data, ${ }^{47}$ we speculate that elevated TGF- $\beta$ signaling is likely a secondary effect of prolonged or excessive hyperoxia exposure and contributes to the progressive fibrosis observed. Two recent studies reported on the effects of hyperoxia exposure within the context of transgenic overexpression of TGF $\beta 1$ and/or genetic abrogation of TGF- $\beta$ signaling (via deletion of the TBRII receptor) on neonatal survival and lung alveolar development. ${ }^{43,57}$ Both studies suggested that the additive effect of hyperoxia and upregulated TGF- $\beta$ signaling was further inhibitory, whereas blocking TGF- $\beta$ signaling during hyperoxia was protective of lung development. Our study differs from these reports in that we used lower concentrations of oxygen (85\% versus $100 \%$ ) and documented not only early down-regulation of TGF $\beta 1$, but also TGF $\beta 2$ and TGF $\beta 3$. It is probable that a fine balance of absolute and/or relative concentrations of TGF- $\beta$ ligand expression is required for maintenance of normal alveolar lung development. Forced genetic overexpression of TGF $\beta 1$ alone likely results in non-physiologic absolute and relative expression levels of TGF- $\beta$ ligands and, therefore, may not accurately recapitulate the physiological responses to neonatal hyperoxia. Our present data, combined with the previously mentioned published works, underline the complex, often contradictory, role of TGF- $\beta$ (and its isoforms) and indicate a need to carefully design studies that focus on clinically appropriate stages of alveolar lung development, as well as use strategies capable of determining the possible benefits of ligand-specific supplementation at physiological levels to protect against neonatal hyperoxic lung injury. Only then will the contribution of altered TGF- $\beta$ signaling to alveolar development be fully elucidated and appropriate treatments to modulate TGF- $\beta$ be designed.

\section{Loss of the TGF- $\beta$ Effector, TGFBI, Underlies Early Alveolar Structural Defects}

We have identified TGFBI as a widely expressed, previously unrecognized, critical component for normal secondary alveolar septation. Not only did we correlate hyperoxia-mediated acute suppression of several stages of the TGF- $\beta$ signaling apparatus and of the TGF- $\beta$-responsive Tgfbi gene, our expression data demonstrated that TGFBI was dynamically expressed within the septal tips (Figures 1 and 4) during alveolar lung development and was then down-regulated at the conclusion of bulk alveolarization. Moreover, Tgfbi-null neonates exhibit both histological and functional deficits in secondary septal morphogenesis. Structurally, the genetic Tgfbi-null lung phenotype is similar to the physiological hyperoxia-induced arrested alveolar septation phenotype at $\mathrm{P} 4$ to P14, with stunted septa and simplification of distal airspaces (Figures 1 and 4). In addition, both the hyperoxia-induced and Tgfbi-null neonatal lungs exhibit diminished proliferation at $\mathrm{P}^{22}$ (Figure 5), altered $\alpha$-SMA myofibroblast marker expression, and ectopic expression of FST (Figures 1 and 6). Our finding that Pdgfr $\alpha$ (a known marker of lung fibroblast progenitors and regulator of myofibroblast differentiation ${ }^{36,38}$ ) is suppressed in P7 Tgfbi-null lungs supports our hypothesis that loss of TGFBI directly interferes with septal morphogenesis. Because the null septal tips display reduced presence of elastin, mislocalized myofibroblasts, and stunted growth, combined with the lack of Pdgfr $\alpha$ expression during the crucial P7 stage of alveolarization, our data suggest that there is an imbalance between structural fibroblasts and myofibroblast populations 
associated with impaired alveolar septation in mouse mutants lacking TGFBI. The prolonged and ectopic expression of both $T g f b i^{-l a c Z}$ reporter and $\alpha$-SMA protein within the null P14 lungs is consistent with the notion that, in the absence of TGFBI, lung fibroblast differentiation is hindered. In addition, these neonatal $T g f b i$ null structural defects are associated with impaired gas diffusion and decreased elastic recoil in adult mice. Combined, these data demonstrate that TGFBI is transiently required for both normal alveolar remodeling and subsequent normal longterm murine lung function.

During perinatal lung development, the interstitial fibroblasts are initially exposed to TGF- $\beta$, a stimulus for myofibroblastic differentiation. ${ }^{58}$ Although signaling through PDGFR $\alpha$ is a critical event for alveolarization, because it is necessary for the appearance of alveolar myofibroblasts, ${ }^{35-38}$ down-regulation of signaling during later stages of alveolar development is required for septal maturation. ${ }^{59}$ In addition, during realveolarization after pneumonectomy, Pdgfr $\alpha$ expressing cells reexpand into the alveolar space, proliferate, and then down-regulate Pdgfr $\alpha$ expression as they increase $\alpha$-SMA expression. Interference with temporal PDGFR $\alpha$ signaling impairs the balance between structural and contractile alveolar fibroblasts, resulting in impaired alveolar septation. $^{37,38,59,60}$

Similar to our Tgfbi-null expression data (Figure 6), tracheal aspirate mesenchymal stromal cells from premature infants developing BPD express lower levels of PDGFR $\alpha,{ }^{61}$ suggesting that defective PDGFR signaling is a primary feature of alveolar septation defects. Our results revealed that both reduced TGF- $\beta$ signaling mediated by hyperoxia and reduced PDGFR signaling mediated by the absence of TGF- $\beta$-responsive TGFBI are both associated with alveolar septal defects. It is not yet clear whether TGF- $\beta$ and PDGFR signaling are coregulated, reciprocally interact, or regulated by one another within myofibroblasts. However, there are pharmacological data that suggest imatinib and nilotinib, two BCR-ABL tyrosine kinase inhibitors, can suppress both pathways simultaneously ${ }^{62}$ to reduce lung fibroblast proliferation. Moreover, TGF- $\beta$ can signal via Smad-independent pathways through c-Abl, and imatinib has been shown to suppress TGF- $\beta$ downstream signaling via inhibition of c-Abl. ${ }^{63}$ It is clear, however, that when TGF- $\beta$ signaling is down-regulated via canonical pSmaddependent $^{47}$ or noncanonical Smad-independent pathways during early alveolarization, ${ }^{37}$ secondary septal morphogenesis is perturbed. It is established that TGF- $\beta$ signaling is exquisitely regulated at both the extracellular and intracellular levels, and that TGF- $\beta$ downstream effectors are not only compartment specific but also temporally regulated within the epithelial, mesenchymal, and immune components of the lung. Our multilayered data support the premise that initial suppression of TGF- $\beta$ ligand signaling via intracellular Smads, as well as loss of key downstream TGF$\beta$ effectors (eg, TGFBI), underlie murine early lung alveolar septation defects. Although beyond the scope of our studies because of the lack of a suitable myofibroblast-restricted driver and inability to specifically test TGF- $\beta 2$ function, our results suggest that supplementation of TGF- $\beta$ (or more likely a downstream effector like TGFBI) from birth to P7 may possibly amend initial hyperoxic lung deficits. Thus, therapeutic manipulation of TGF- $\beta$ signaling to ameliorate or prevent BPD in patients remains a tempting, but extremely challenging, prospect.

\section{TGFBI Is Required for Proper Lung Elastin Morphogenesis and Normal Lung Function}

Given the structural phenotypes and expression profiling similarities resulting from neonatal hyperoxia and $T g f b i$ deficiency, in addition to the four FAS1 domains, TGFBI includes a tripeptide Arg-Gly-Asp (RGD) motif. ${ }^{64}$ More important, TGFBI has been shown to influence cell-cell and cell-substratum interactions, including an ability to bind integrins in lung fibroblasts and vascular smooth muscle cells, as well as laminins, fibronectin, type I/II/IV collagens, and elastin. These influence cell proliferation, adhesion, and migration, ${ }^{65-71}$ all of which are important for lung development. Elastic fibers are composite structures (containing both amorphous elastin and microfibrils), and generation of a functional fiber occurs in a well-defined temporal sequence during lung tissue development. ${ }^{72}$ Collagen-elastin scaffolds and the elastic fiber-microfibril interface are thought to influence elastic fiber assembly. Previous work in mechanically ventilated mouse pups and preterm lambs has implicated elastin scaffold assembly as a critical component of alveolar septation. ${ }^{73,74}$ Although it is not yet known whether TGFBI plays a scaffold function during alveolarization, its coassociation with elastin microfibrils and collagens, ${ }^{68}$ its modulation of both cellsubstratum and cell-cell interactions, ${ }^{70,71,75}$ and its spatial localization at the septal tips make this a likely role. The fact that we did not find any alteration of elastin mRNA levels in $T g f b i$ nulls, but detected a lack of elastin fibrils at the septal tips, suggests that an absence of TGFBI most likely compromises microfibril formation and normal deposition. Moreover, because TGFBI shares significant homology with periostin, which plays a scaffolding function during cardiovascular and skin tissue morphogenesis, ${ }^{28,76} T g f b i$ deficiency could result in a failure of accessory proteins for elastin fiber assembly localizing to nascent microfibrils. Finally, the decreased elastance we observed in lungs of adult $T g f b i$-null mice suggests that TGFBI may be important for proper lung elastin development and function.

\section{TGFBI Nulls Exhibit Additional TGF- $\beta$-Pathway Gene Alterations Related to Lung Fibroblast Maldevelopment}

Significantly, we saw up-regulation of FST gene and protein expression coincident with reduced expression of TGFBI, both secondary to hyperoxia and within $T g f b i$ nulls (Figures 1 and 6). FST contains a heparin-binding 
residue that binds and sequesters it to proteoglycans in the ECM. ${ }^{77}$ Likewise, TGFBI interacts directly with the proteoglycans, biglycan and decorin, in the ECM to form ternary complexes with collagen VI. ${ }^{78}$ Although a direct relationship has not been explored, it is plausible that TGFBI may, therefore, modulate sequestration of FST within the ECM, and that the TGFBI deficiency result is loss of negative regulation of FST expression. Indeed, administration of heparin interferes with FST/ECM binding and results in the rapid increase of circulating FST levels. ${ }^{79}$ Further investigation to determine the direct influence of TGFBI on FST/ECM interactions is needed to understand the possible underlying mechanism leading to ectopic up-regulation of FST. In addition, Serpinel was also up-regulated in Tgfbi-null lungs (Figure 6). Significantly, FST and serpine 1 are each individually associated with abnormal maturation and reduced proliferation of lung fibroblasts, ${ }^{26,39,80}$ both of which we observed in developing hyperoxic and Tgfbi-null lungs, and suggest dysregulation of the septal ECM morphogenesis. Because FST is not normally expressed within the neonatal lung and its primary function is to bind and bioneutralize members of the TGF- $\beta$ superfamily, its ectopic up-regulation may serve to further suppress TGF- $\beta$ signaling, resulting in blunted septal tips and reduced alveolarization. Similarly, the ectopic expression of Serpinel (alias plasminogen activator inhibitor type 1) may well result in decreased plasmin-mediated matrix metalloproteinase activation and reduced ECM remodeling during septal elongation and terminal air-sac subdivision, resulting in the observed Tgfbi-null lung phenotype.

\section{Conclusions}

Most infants born extremely preterm will develop BPD because of inhibited saccular and alveolar lung development. ${ }^{7,9}$ Although relatively brief, lung injury incurred during the initial hospitalization affects a critical window of lung development and results in long-standing deficits in alveolar lung structure and function. ${ }^{5,81,82}$ Attempts at preventing BPD have been largely unsuccessful, in part, because of an inadequate understanding of BPD pathogenesis. Identifying novel effectors of saccular and early alveolar development, as well as carefully understanding the developmentally appropriate context of aberrant signaling pathways after preterm birth, is critical to design therapies that promote normal alveolar lung development and function.

\section{Acknowledgments}

We thank both the Indiana University School of Medicine Electron Microscopy Research Core and Indiana University Transgenic and Knockout Mouse Core for assistance and Drs. Wei Li and Weinian Shou (Indiana University School of Medicine) for help with targeting vector design and generation.

\section{References}

1. Kimura J, Deutsch GH: Key mechanisms of early lung development. Pediatr Dev Pathol 2007, 10:335-347

2. Burri PH: Fetal and postnatal development of the lung. Annu Rev Physiol 1984, 46:617-628

3. Ahlfeld SK, Conway SJ: Aberrant signaling pathways of the lung mesenchyme and their contributions to the pathogenesis of bronchopulmonary dysplasia. Birth Defects Res A Clin Mol Teratol 2012, 94: $3-15$

4. McGowan SE: Paracrine cellular and extracellular matrix interactions with mesenchymal progenitors during pulmonary alveolar septation. Birth Defects Res A Clin Mol Teratol 2014, 100:227-239

5. Ahlfeld SK, Conway SJ: Assessment of inhibited alveolar-capillary membrane structural development and function in bronchopulmonary dysplasia. Birth Defects Res A Clin Mol Teratol 2014, 100: $168-179$

6. Husain AN, Siddiqui NH, Stocker JT: Pathology of arrested acinar development in postsurfactant bronchopulmonary dysplasia. Hum Pathol 1998, 29:710-717

7. Jobe AH: The new bronchopulmonary dysplasia. Curr Opin Pediatr 2011, 23:167-172

8. Doyle LW, Faber B, Callanan C, Freezer N, Ford GW, Davis NM: Bronchopulmonary dysplasia in very low birth weight subjects and lung function in late adolescence. Pediatrics 2006, 118:108-113

9. Stoll BJ, Hansen NI, Bell EF, Shankaran S, Laptook AR, Walsh MC, Hale EC, Newman NS, Schibler K, Carlo WA, Kennedy KA, Poindexter BB, Finer NN, Ehrenkranz RA, Duara S, Sanchez PJ, O'Shea TM, Goldberg RN, Van Meurs KP, Faix RG, Phelps DL, Frantz ID III, Watterberg KL, Saha S, Das A, Higgins RD: Eunice Kennedy Shriver National Institute of Child Health and Human Development Neonatal Research Network: Neonatal outcomes of extremely preterm infants from the NICHD neonatal research network. Pediatrics 2010, 126:443-456

10. Abman SH, Conway SJ: Developmental determinants and changing patterns of respiratory outcomes after preterm birth. Birth Defects Res A Clin Mol Teratol 2014, 100:127-133

11. Thibeault DW, Mabry SM, Ekekezie II, Zhang X, Truog WE: Collagen scaffolding during development and its deformation with chronic lung disease. Pediatrics 2003, 111:766-776

12. Thibeault DW, Mabry SM, Ekekezie II, Truog WE: Lung elastic tissue maturation and perturbations during the evolution of chronic lung disease. Pediatrics 2000, 106:1452-1459

13. Ignotz RA, Massague J: Transforming growth factor-beta stimulates the expression of fibronectin and collagen and their incorporation into the extracellular matrix. J Biol Chem 1986, 261:4337-4345

14. Alejandre-Alcázar MA, Kwapiszewska G, Reiss I, Amarie OV, Marsh LM, Sevilla-Pérez J, Wygrecka M, Eul B, Köbrich S, Hesse M, Schermuly RT, Seeger W, Eickelberg O, Morty RE: Hyperoxia modulates TGF-Beta/BMP signaling in a mouse model of bronchopulmonary dysplasia. Am J Physiol Lung Cell Mol Physiol 2007, 292:L537-L549

15. McGowan SE, Jackson SK, Olson PJ, Parekh T, Gold LI: Exogenous and endogenous transforming growth factors-beta influence elastin gene expression in cultured lung fibroblasts. Am J Respir Cell Mol Biol 1997, 17:25-35

16. Wendel DP, Taylor DG, Albertine KH, Keating MT, Li DY: Impaired distal airway development in mice lacking elastin. Am J Respir Cell Mol Biol 2000, 23:320-326

17. Heldin $\mathrm{CH}$, Landstrom M, Moustakas A: Mechanism of TGF-beta signaling to growth arrest, apoptosis, and epithelial-mesenchymal transition. Curr Opin Cell Biol 2009, 21:166-176 
18. Alejandre-Alcazar MA, Michiels-Corsten M, Vicencio AG, Reiss I, Ryu J, de Krijger RR, Haddad GG, Tibboel D, Seeger W, Eickelberg O, Morty RE: TGF-beta signaling is dynamically regulated during the alveolarization of rodent and human lungs. Dev Dyn 2008, 237:259-269

19. Warner BB, Stuart LA, Papes RA, Wispe JR: Functional and pathological effects of prolonged hyperoxia in neonatal mice. Am J Physiol 1998, 275:L110-L117

20. Yee M, Chess PR, McGrath-Morrow SA, Wang Z, Gelein R, Zhou R, Dean DA, Notter RH, O'Reilly MA: Neonatal oxygen adversely affects lung function in adult mice without altering surfactant composition or activity. Am J Physiol Lung Cell Mol Physiol 2009, 297:L641-L649

21. Yee M, White RJ, Awad HA, Bates WA, McGrath-Morrow SA O'Reilly MA: Neonatal hyperoxia causes pulmonary vascular disease and shortens life span in aging mice. Am J Pathol 2011, 178: $2601-2610$

22. Ahlfeld SK, Gao Y, Wang J, Horgusluoglu E, Bolanis E, Clapp DW, Conway SJ: Periostin downregulation is an early marker of inhibited neonatal murine lung alveolar septation. Birth Defects Res A Clin Mol Teratol 2013, 97:373-385

23. Ahlfeld SK, Gao Y, Conway SJ, Tepper RS: Relationship of structural to functional impairment during alveolar-capillary membrane development. Am J Pathol 2015, 185:913-919

24. Rios H, Koushik SV, Wang H, Wang J, Zhou HM, Lindsley A, Rogers R, Chen Z, Maeda M, Kruzynska-Frejtag A, Feng JQ, Conway SJ: Periostin null mice exhibit dwarfism, incisor enamel defects, and an early-onset periodontal disease-like phenotype. Mol Cell Biol 2005, 25:11131-11144

25. Snider P, Simmons O, Wang J, Hoang C, Conway S: Ectopic noggin in a population of nfatc1 lineage endocardial progenitors induces embryonic lethality. J Cardiovasc Dev Dis 2014, 1:214-236

26. Ohga E, Matsuse T, Teramoto S, Ouchi Y: Activin receptors are expressed on human lung fibroblast and activin A facilitates fibroblast-mediated collagen gel contraction. Life Sci 2000, 66: $1603-1613$

27. Lindsley A, Li W, Wang J, Maeda N, Rogers R, Conway SJ: Comparison of the four mouse fasciclin-containing genes expression patterns during valvuloseptal morphogenesis. Gene Expr Patterns 2005, 5:593-600

28. Snider P, Standley KN, Wang J, Azhar M, Doetschman T, Conway SJ: Origin of cardiac fibroblasts and the role of periostin. Circ Res 2009, 105:934-947

29. Snider P, Simmons O, Rogers R, Young R, Gosnell M, Conway SJ: Notochordal and foregut abnormalities correlate with elevated neural crest apoptosis in patch embryos. Birth Defects Res A Clin Mol Teratol 2011, 91:551-564

30. Simmons O, Bolanis EM, Wang J, Conway SJ: In situ hybridization (both radioactive and nonradioactive) and spatiotemporal gene expression analysis. Methods Mol Biol 2014, 1194:225-244

31. Myllarniemi M, Tikkanen J, Hulmi JJ, Pasternack A, Sutinen E, Ronty M, Lepparanta O, Ma H, Ritvos O, Koli K: Upregulation of activin-B and follistatin in pulmonary fibrosis: a translational study using human biopsies and a specific inhibitor in mouse fibrosis models. BMC Pulm Med 2014, 14:170

32. Nakanishi H, Sugiura T, Streisand JB, Lonning SM, Roberts JD: TGF-beta-neutralizing antibodies improve pulmonary alveologenesis and vasculogenesis in the injured newborn lung. Am J Physiol Lung Cell Mol Physiol 2007, 293:L151-L161

33. Du Y, Guo M, Whitsett JA, Xu Y: "LungGENS": a web-based tool for mapping single-cell gene expression in the developing lung. Thorax 2015, 70:1092-1094

34. Jakkula M, Le Cras TD, Gebb S, Hirth KP, Tuder RM, Voelkel NF, Abman SH: Inhibition of angiogenesis decreases alveolarization in the developing rat lung. Am J Physiol Lung Cell Mol Physiol 2000, 279:L600-L607

35. Boström H, Gritli-Linde A, Betsholtz C: PDGF-a/PDGF alphareceptor signaling is required for lung growth and the formation of alveoli but not for early lung branching morphogenesis. Dev Dyn 2002, 223:155-162

36. Bostrom H, Willetts K, Pekny M, Leveen P, Lindahl P, Hedstrand H, Pekna M, Hellstrom M, Gebre-Medhin S, Schalling M, Nilsson M, Kurland S, Tornell J, Heath JK, Betsholtz C: PDGF-A signaling is a critical event in lung alveolar myofibroblast development and alveogenesis. Cell 1996, 85:863-873

37. Lau M, Masood A, Yi M, Belcastro R, Li J, Tanswell AK: Long-term failure of alveologenesis after an early short-term exposure to a PDGF-receptor antagonist. Am J Physiol Lung Cell Mol Physiol 2011, 300:L534-L547

38. Chen L, Acciani T, Le Cras T, Lutzko C, Perl AK: Dynamic regulation of platelet-derived growth factor receptor alpha expression in alveolar fibroblasts during realveolarization. Am J Respir Cell Mol Biol 2012, 47:517-527

39. Aoki F, Kurabayashi M, Hasegawa Y, Kojima I: Attenuation of bleomycin-induced pulmonary fibrosis by follistatin. Am J Respir Crit Care Med 2005, 172:713-720

40. Kotecha S, Wangoo A, Silverman M, Shaw RJ: Increase in the concentration of transforming growth factor beta- 1 in bronchoalveolar lavage fluid before development of chronic lung disease of prematurity. J Pediatr 1996, 128:464-469

41. Lecart C, Cayabyab R, Buckley S, Morrison J, Kwong KY, Warburton D, Ramanathan R, Jones CA, Minoo P: Bioactive transforming growth factor-beta in the lungs of extremely low birthweight neonates predicts the need for home oxygen supplementation. Biol Neonate 2000, 77:217-223

42. Bozyk PD, Bentley JK, Popova AP, Anyanwu AC, Linn MD, Goldsmith AM, Pryhuber GS, Moore BB, Hershenson MB: Neonatal periostin knockout mice are protected from hyperoxia-induced alveolar simplication. PLoS One 2012, 7:e31336

43. Sureshbabu A, Syed MA, Boddupalli CS, Dhodapkar MV, Homer RJ, Minoo P, Bhandari V: Conditional overexpression of TGFbetal promotes pulmonary inflammation, apoptosis and mortality via TGFbetaR2 in the developing mouse lung. Respir Res 2015, 16:4

44. Gauldie J, Galt T, Bonniaud P, Robbins C, Kelly M, Warburton D: Transfer of the active form of transforming growth factor beta 1 gene to newborn rat lung induces changes consistent with bronchopulmonary dysplasia. Am J Pathol 2003, $163: 2575-2584$

45. Vicencio AG, Lee CG, Cho SJ, Eickelberg O, Chuu Y, Haddad GG, Elias JA: Conditional overexpression of bioactive transforming growth factor beta 1 in neonatal mouse lung: a new model for bronchopulmonary dysplasia? Am J Respir Cell Mol Biol 2004, 31: 650-656

46. Chen H, Zhuang F, Liu YH, Xu B, Del Moral P, Deng W, Chai Y, Kolb M, Gauldie J, Warburton D, Moses HL, Shi W: TGF-beta receptor II in epithelia versus mesenchyme plays distinct roles in the developing lung. Eur Respir J 2008, 32:285-295

47. Chen H, Sun J, Buckley S, Chen C, Warburton D, Wang X-F, Shi W: Abnormal mouse lung alveolarization caused by Smad3 deficiency is a developmental antecedent of centrilobular emphysema. Am J Physiol Lung Cell Mol Physiol 2005, 288:L683-L691

48. Colarossi C, Chen Y, Obata H, Jurukovski V, Fontana L, Dabovic B, Rifkin DB: Lung alveolar septation defects in Ltbp-3-null mice. Am J Pathol 2005, 167:419-428

49. Sterner-Kock A, Thorey IS, Koli K, Wempe F, Otte J, Bangsow T, Kuhlmeier K, Kirchner T, Jin S, Keski-Oja J, von Melchner H: Disruption of the gene encoding the latent transforming growth factor-beta binding protein 4 (LTBP-4) causes abnormal lung development, cardiomyopathy, and colorectal cancer. Genes Dev 2002, 16:2264-2273

50. Shull MM, Ormsby I, Kier AB, Pawlowski S, Diebold RJ, Yin M, Allen R, Sidman C, Proetzel G, Calvin D, Annunziata N, Doetschman T: Targeted disruption of the mouse transforming growth factor beta 1 gene results in multifocal inflammatory disease. Nature 1992, 359:693-699 
51. Maniscalco WM, Sinkin RA, Watkins RH, Campbell MH: Transforming growth factor-beta 1 modulates type II cell fibronectin and surfactant protein C expression. Am J Physiol 1994, 267:L569-L577

52. Serra R, Pelton RW, Moses HL: TGF beta 1 inhibits branching morphogenesis and $\mathrm{N}$-myc expression in lung bud organ cultures. Development 1994, 120:2153-2161

53. Kaartinen V, Voncken JW, Shuler C, Warburton D, Bu D, Heisterkamp N, Groffen J: Abnormal lung development and cleft palate in mice lacking TGF-beta 3 indicates defects of epithelialmesenchymal interaction. Nat Genet 1995, 11:415-421

54. Pelton RW, Johnson MD, Perkett EA, Gold LI, Moses HL: Expression of transforming growth factor-beta 1, -beta 2, and -beta 3 mRNA and protein in the murine lung. Am J Respir Cell Mol Biol 1991, 5:522-530

55. Liu J, Tseu I, Wang J, Tanswell K, Post M: Transforming growth factor beta2, but not beta1 and beta3, is critical for early rat lung branching. Dev Dyn 2000, 217:343-360

56. Sanford LP, Ormsby I, Gittenberger-de Groot AC, Sariola H, Friedman R, Boivin GP, Cardell EL, Doetschman T: TGFbeta2 knockout mice have multiple developmental defects that are nonoverlapping with other TGFbeta knockout phenotypes. Development 1997, 124:2659-2670

57. Li Z, Choo-Wing R, Sun H, Sureshbabu A, Sakurai R, Rehan VK, Bhandari V: A potential role of the JNK pathway in hyperoxia-induced cell death, myofibroblast transdifferentiation and TGF-beta1-mediated injury in the developing murine lung. BMC Cell Biol 2011, 12:54

58. Hashimoto S, Gon Y, Takeshita I, Matsumoto K, Maruoka S, Horie T: Transforming growth factor-betal induces phenotypic modulation of human lung fibroblasts to myofibroblast through a cJun-NH2-terminal kinase-dependent pathway. Am J Respir Crit Care Med 2001, 163:152-157

59. McGowan SE, McCoy DM: Fibroblasts expressing PDGF-receptoralpha diminish during alveolar septal thinning in mice. Pediatr Res 2011, 70:44-49

60. Perl AK, Gale E: FGF signaling is required for myofibroblast differentiation during alveolar regeneration. Am J Physiol Lung Cell Mol Physiol 2009, 297:L299-L308

61. Popova AP, Bentley JK, Cui TX, Richardson MN, Linn MJ, Lei J, Chen Q, Goldsmith AM, Pryhuber GS, Hershenson MB: Reduced platelet-derived growth factor receptor expression is a primary feature of human bronchopulmonary dysplasia. Am J Physiol Lung Cell Mol Physiol 2014, 307:L231-L239

62. Rhee CK, Lee SH, Yoon HK, Kim SC, Lee SY, Kwon SS, Kim YK, Kim KH, Kim TJ, Kim JW: Effect of nilotinib on bleomycin-induced acute lung injury and pulmonary fibrosis in mice. Respiration 2011, 82:273-287

63. Wang S, Wilkes MC, Leof EB, Hirschberg R: Noncanonical TGFbeta pathways, mTORC1 and Abl, in renal interstitial fibrogenesis. Am J Physiol Renal Physiol 2010, 298:F142-F149

64. Schorderet DF, Menasche M, Morand S, Bonnel S, Buchillier V, Marchant D, Auderset K, Bonny C, Abitbol M, Munier FL: Genomic characterization and embryonic expression of the mouse Bigh3 (Tgfbi) gene. Biochem Biophys Res Commun 2000, 274:267-274

65. Billings PC, Whitbeck JC, Adams CS, Abrams WR, Cohen AJ, Engelsberg BN, Howard PS, Rosenbloom J: The transforming growth factor-beta-inducible matrix protein (beta)ig-h3 interacts with fibronectin. J Biol Chem 2002, 277:28003-28009

66. Hashimoto K, Noshiro M, Ohno S, Kawamoto T, Satakeda H, Akagawa Y, Nakashima K, Okimura A, Ishida H, Okamoto T, Pan H, Shen M, Yan W, Kato Y: Characterization of a cartilage-derived 66$\mathrm{kDa}$ protein (RGD-CAP/beta ig-h3) that binds to collagen. Biochim Biophys Acta 1997, 1355:303-314

67. Thapa N, Lee BH, Kim IS: TGFBIp/betaig-h3 protein: a versatile matrix molecule induced by TGF-beta. Int J Biochem Cell Biol 2007, 39:2183-2194

68. Gibson MA, Kumaratilake JS, Cleary EG: Immunohistochemical and ultrastructural localization of MP78/70 (betaig-h3) in extracellular matrix of developing and mature bovine tissues. J Histochem Cytochem 1997, 45:1683-1696

69. Kim JE, Kim SJ, Lee BH, Park RW, Kim KS, Kim IS: Identification of motifs for cell adhesion within the repeated domains of transforming growth factor-beta-induced gene, betaig-h3. J Biol Chem 2000, 275:30907-30915

70. Lee BH, Bae JS, Park RW, Kim JE, Park JY, Kim IS: Betaig-h3 triggers signaling pathways mediating adhesion and migration of vascular smooth muscle cells through alphavbeta5 integrin. Exp Mol Med 2006, 38:153-161

71. Bae JS, Lee SH, Kim JE, Choi JY, Park RW, Yong Park J, Park HS, Sohn YS, Lee DS, Bae Lee E, Kim IS: Betaig-h3 supports keratinocyte adhesion, migration, and proliferation through alpha3betal integrin. Biochem Biophys Res Commun 2002, 294:940-948

72. Shifren A, Durmowicz AG, Knutsen RH, Hirano E, Mecham RP: Elastin protein levels are a vital modifier affecting normal lung development and susceptibility to emphysema. Am J Physiol Lung Cell Mol Physiol 2007, 292:L778-L787

73. Bland RD, Ertsey R, Mokres LM, Xu L, Jacobson BE, Jiang S, Alvira CM, Rabinovitch M, Shinwell ES, Dixit A: Mechanical ventilation uncouples synthesis and assembly of elastin and increases apoptosis in lungs of newborn mice: prelude to defective alveolar septation during lung development? Am J Physiol Lung Cell Mol Physiol 2008, 294:L3-L14

74. Bland RD, Xu L, Ertsey R, Rabinovitch M, Albertine KH, Wynn KA, Kumar VH, Ryan RM, Swartz DD, Csiszar K, Fong KS: Dysregulation of pulmonary elastin synthesis and assembly in preterm lambs with chronic lung disease. Am J Physiol Lung Cell Mol Physiol 2007, 292:L1370-L1384

75. Skonier J, Bennett K, Rothwell V, Kosowski S, Plowman G, Wallace P, Edelhoff S, Disteche C, Neubauer M, Marquardt H, Rodgers J, Purchio AF: Beta ig-h3: a transforming growth factorbeta-responsive gene encoding a secreted protein that inhibits cell attachment in vitro and suppresses the growth of $\mathrm{CHO}$ cells in nude mice. DNA Cell Biol 1994, 13:571-584

76. Norris RA, Damon B, Mironov V, Kasyanov V, Ramamurthi A, Moreno-Rodriguez R, Trusk T, Potts JD, Goodwin RL, Davis J, Hoffman S, Wen X, Sugi Y, Kern CB, Mjaatvedt CH, Turner DK, Oka T, Conway SJ, Molkentin JD, Forgacs G, Markwald RR: Periostin regulates collagen fibrillogenesis and the biomechanical properties of connective tissues. J Cell Biochem 2007, 101:695-711

77. Nakamura T, Sugino K, Titani K, Sugino H: Follistatin, an activinbinding protein, associates with heparan sulfate chains of proteoglycans on follicular granulosa cells. J Biol Chem 1991, 266: 19432-19437

78. Reinboth B, Thomas J, Hanssen E, Gibson MA: Beta ig-h3 interacts directly with biglycan and decorin, promotes collagen VI aggregation, and participates in ternary complexing with these macromolecules. J Biol Chem 2006, 281:7816-7824

79. Phillips DJ, Jones KL, McGaw DJ, Groome NP, Smolich JJ, Parsson H, de Kretser DM: Release of activin and follistatin during cardiovascular procedures is largely due to heparin administration. J Clin Endocrinol Metab 2000, 85:2411-2415

80. Lindahl GE, Stock CJ, Shi-Wen X, Leoni P, Sestini P, Howat SL, Bou-Gharios G, Nicholson AG, Denton CP, Grutters JC, Maher TM, Wells AU, Abraham DJ, Renzoni EA: Microarray profiling reveals suppressed interferon stimulated gene program in fibroblasts from scleroderma-associated interstitial lung disease. Respir Res 2013, 14:80

81. Lum S, Kirkby J, Welsh L, Marlow N, Hennessy E, Stocks J: Nature and severity of lung function abnormalities in extremely pre-term children at 11 years of age. Eur Respir J 2011, 37: 1199-1207

82. Wong PM, Lees AN, Louw J, Lee FY, French N, Gain K, Murray CP, Wilson A, Chambers DC: Emphysema in young adult survivors of moderate-to-severe bronchopulmonary dysplasia. Eur Respir J 2008, $32: 321-328$ 